\title{
Progress in Paleoclimate Modeling*
}

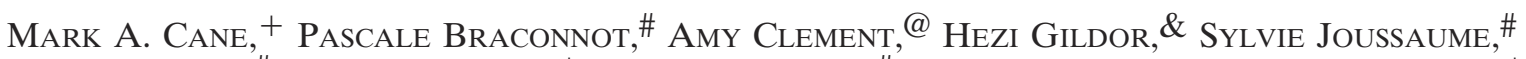 \\ Masa Kageyama, " Myriam Khodri, ${ }^{+}$Didier Paillard, ${ }^{\#}$ Simon Tett, ${ }^{*} *$ and Eduardo Zorita ++ \\ ${ }^{+}$Lamont-Doherty Earth Observatory, Columbia University, Palisades, New York \\ \# Institut Pierre Simon Laplace/Laboratoire des Sciences du Climat et de l'Environnement, UMR CEA-CNRS, Gif-sur-Yvette, France \\ @ Rosenstiel School of Marine and Atmospheric Sciences, University of Miami, Miami, Florida \\ \& Department of Environmental Sciences, Weizmann Institute of Science, Rehovot, Israel \\ ** Hadley Centre, Met Office, Exeter, and University of Reading, Reading, United Kingdom \\ ++ GKSS Forschungszentrum, Geesthacht, Germany
}

(Manuscript received 16 September 2004, in final form 14 August 2005)

\begin{abstract}
This paper briefly surveys areas of paleoclimate modeling notable for recent progress. New ideas, including hypotheses giving a pivotal role to sea ice, have revitalized the low-order models used to simulate the time evolution of glacial cycles through the Pleistocene, a prohibitive length of time for comprehensive general circulation models (GCMs). In a recent breakthrough, however, GCMs have succeeded in simulating the onset of glaciations. This occurs at times (most recently, $115 \mathrm{kyr}$ B.P.) when high northern latitudes are cold enough to maintain a snow cover and tropical latitudes are warm, enhancing the moisture source. More generally, the improvement in models has allowed simulations of key periods such as the Last Glacial Maximum and the mid-Holocene that compare more favorably and in more detail with paleoproxy data. These models now simulate ENSO cycles, and some of them have been shown to reproduce the reduction of ENSO activity observed in the early to middle Holocene. Modeling studies have demonstrated that the reduction is a response to the altered orbital configuration at that time. An urgent challenge for paleoclimate modeling is to explain and to simulate the abrupt changes observed during glacial epochs (i.e., Dansgaard-Oescher cycles, Heinrich events, and the Younger Dryas). Efforts have begun to simulate the last millennium. Over this time the forcing due to orbital variations is less important than the radiance changes due to volcanic eruptions and variations in solar output. Simulations of these natural variations test the models relied on for future climate change projections. They provide better estimates of the internal and naturally forced variability at centennial time scales, elucidating how unusual the recent global temperature trends are.
\end{abstract}

\section{Introduction}

Paleoclimate is a larger and grander topic than Climate Variability and Predictability (CLIVAR), the subject of this entire special section. It encompasses a far greater range of time scales and a greater range of physical and biogeochemical processes. A decade ago, the mismatch between computing capability and the

* Lamont-Doherty Earth Observatory Contribution Number 6811.

Corresponding author address: Mark A. Cane, LamontDoherty Earth Observatory, Columbia University, 61 Route 9W, Palisades, NY 10964-8000.

E-mail: mcane@ldeo.columbia.edu length of integrations demanded by most paleoclimate problems severely limited what could be accomplished with general circulation class models. The great expansion of computing resources in the last decade still leaves a mismatch, but much more can now be done, and much more has been done. Moreover, the great improvement in climate models has made them far more useful tools in paleoclimate research. Key results reviewed in section 3, for example, depend on a coupled ocean-atmosphere model whose climate bears more than a passing resemblance to reality. Other problems require models for land surface processes, ocean chemistry and biology, and the cryosphere, components that were inadequate or nonexistent not long ago. (They are still inadequate for many problems, but progress has been impressive.) In seeking the causes of abrupt climate change, or the character of glacial-inter- 
glacial cycles, none of these processes can be dismissed out of hand. This need to consider the climate system in the broadest terms is not only a grand intellectual challenge, but has become distressingly relevant as we force the climate system beyond the limits of what is in the instrumental record.

Paleoclimate, in common with other earth sciences, is data driven. The decade's advances in modeling are unimaginable without the enormous increase in the quantity and precision of paleoclimate proxy data. Two of the topics we discuss below, paleo-ENSO and abrupt change, did not exist until there were methods to create high-resolution records. For other topics, the observational picture has become far less fuzzy, allowing many more tests of model against data. Though serious dating issues remain, the widespread use of time scales based on ice cores has allowed disparate data to be brought together with far greater confidence.

A decade ago it might have been possible to do a reasonably comprehensive review of paleoclimate modeling as a journal article. Now it would require booklength treatment. Rather than attempt the impossible, here we have chosen a few key topics judged to have some particular lessons and points of contact with CLIVAR science. This has meant leaving out huge tracts of fascinating and important science. We include nothing from earlier than about $800000 \mathrm{yr}$ (800 kyr) ago, omitting the important questions of why there was a transition from a dominant period of $41 \mathrm{kyr}$ to one of $100 \mathrm{kyr}$ at that time and why glaciation set on $2.73 \mathrm{Myr}$ ago. We say little to nothing about interesting recent work on the role of lithospheric rebound, greenhouses gases, equable climate, the Eocene, the impact of tectonic changes, and a host of other topics. The topics we do treat are not covered comprehensively in most cases; instead a few examples are pursued to some depth. Individual sections are independent of each other, but the whole paper is greater than the sum of the sections.

In section 2 we discuss recent modeling work on the causes of the glacial-interglacial cycles prominent in the last $800 \mathrm{kyr}$. Since it is not feasible to integrate GCMs for hundreds of thousands of years, this topic remains largely the domain of low-order models. The importance of threshold behavior is emphasized, as is the idea that orbital changes are the pacemaker of the climate system rather than the driver. In this view, positive feedbacks internal to the climate system are responsible for the 100-kyr cycle, with the orbital forcing setting its phase. We discuss one particular low-order model at some length. This model gives a lead role to sea ice, an idea with clear implications for future climate.

Section 3 reports important progress on a key ele- ment of glacial cycles, the onset of glaciation. This work features GCMs and demonstrates the critical importance of water vapor transports. It also shows that the data cannot be explained without taking account of coupled ocean-atmosphere dynamical processes. Section 4 reviews progress in GCM simulations of two signature periods, the Last Glacial Maximum (LGM) and the middle Holocene. Results from the Paleoclimate Model Intercomparison Project (PMIP), which constitute a multimodel report on the state of the art, have clarified the role of the ocean and vegetation feedbacks in the climate system.

Section 5 addresses the least understood of our topics, abrupt climate change. The discussion here is largely conceptual, reflecting our lack of understanding of the causes of the abrupt climate changes in the paleoproxy record, and our very limited progress in modeling these changes. While the paradigmatic abrupt changes, Dansgaard-Oeschger cycles and Heinrich events, are millennial, the transitions between warm and cold states occur within decades. We are now overlapping with CLIVAR time scales. Section 6 shows that we have gained an understanding of the variations in the character of the El Niño-Southern Oscillation (ENSO) cycle seen in paleoproxy data. The richest observational picture is in the Holocene, and model simulations capture the major features. The Bjerknes feedback (explained below), which is at the core of our understanding of the model ENSO cycle, turns out to be the key to understanding how small changes in orbital configuration lead to substantial changes in ENSO. Section 7, which discusses modeling of the past millennium, intersects with CLIVAR time scales and CLIVAR issues. A key question is how much of the climate variability in the past $1000 \mathrm{yr}$ is attributable to irradiance changes due to volcanic eruptions and solar variability. There are obvious implications for the climate of the twentieth century, and the century to come. Section 8 offers concluding remarks.

\section{Low-order models of glacial cycles}

\section{a. Phenomenology}

Various paleoclimate proxies (Petit et al. 1999; Imbrie et al. 1984) indicate that during the past $800000 \mathrm{yr}$ (the late Pleistocene), the glacial-interglacial cycles were characterized by a pronounced 100000 yr (100 kyr) oscillation, with additional weaker spectral peaks at 41 and $23 \mathrm{kyr}$ and an asymmetric saw-tooth structure marked by the slow buildup of ice sheets and the relatively abrupt melting. In the cool phase global average temperature is about $5^{\circ} \mathrm{C}$ colder than today and sea level is about $120 \mathrm{~m}$ lower. 


\section{model results}

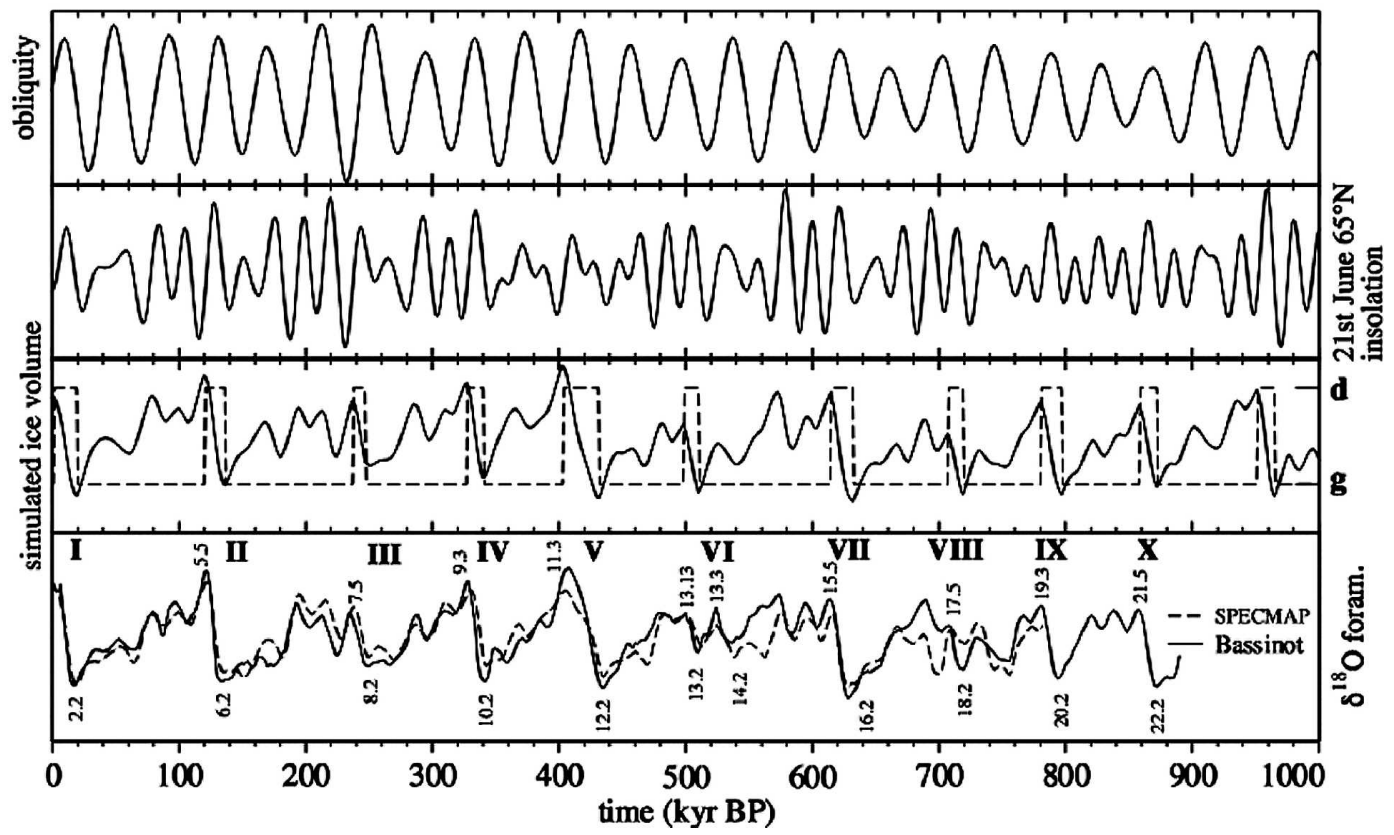

FIG. 1. (from top to bottom) Obliquity, June solstice insolation at $65^{\circ} \mathrm{N}$, modeled ice volume, and proxies for ice volume from Bassinot et al. (1994) and SPECMAP (Imbrie et al. 1984). Bold roman numerals are terminations, and light decimal numbers indicate marine isotope stages (from Parrenin and Paillard 2003).

Variation in incoming solar insolation resulting from secular changes in the eccentricity of the earth's orbit around the sun, in the tilt of the earth's axis relative to the plan of orbit (obliquity), and in the precession of the equinoxes seems a natural candidate for a glacial theory given its time scale and potential climatic effects. As reviewed by Paillard (2001), such theories were proposed as early as the nineteenth century. These theories are now referred to as the Milankovitch theory or the astronomical theory. The mathematician Milankovitch suggested that the solar radiation during the boreal summer season is the critical climatic factor, as cold summers allow the survival of new snow cover from the previous winter season. He also accurately calculated the time variations of the different orbital parameters (Milankovitch 1941). However, the dominant peaks in the power spectrum of the insolation are those of the precession and obliquity, which suggest dominant frequencies of 19-, 23-, and 41-kyr periods, which is not in agreement with the dominant 100-kyr climatic signal.

A satisfying model, or mechanism, for the glacialinterglacial cycles should explain the following observed characteristics.

1) The roughly $100 \mathrm{kyr}$ between glacial maximum during the past $800 \mathrm{kyr}$.

2) The asymmetric sawtooth structure of long glaciations ( $\sim 90 \mathrm{kyr})$ and short deglaciations ( $\sim 5-10 \mathrm{kyr})$.
3) The relatively good correlation with Milankovitch solar variations despite the small changes in earth insolation on a $100-\mathrm{kyr}$ time scale.

4) The nearly synchronous changes in both hemispheres.

5) The glacial-interglacial atmospheric $\mathrm{CO}_{2}$ variations. During glaciation, atmospheric concentration of $\mathrm{CO}_{2}$ gradually declines and reaches a minimum of about $200 \mathrm{ppm}$ during glacial maximum, and it then rises relatively rapidly to a concentration of about $280 \mathrm{ppm}$ at the end of the glacial termination.

If one relies on the Milankovitch theory to explain the ice ages, additional issues should be addressed (Paillard 2001; Parrenin and Paillard 2003; Karner and Muller 2000; Imbrie et al. 1993).

6) The absence of cycles at $400 \mathrm{kyr}$, the major periodicity of eccentricity.

7) The stage-11 problem (transition V). Approximately $400 \mathrm{kyr}$ ago, the earth's orbit was almost circular. Hence seasonal changes in insolation were very small. Milankovitch theory predicts a small glacial-interglacial transition but, it was probably the most intense (Fig. 1).

8) The stage-7 problem (transition III). Approximately 230 kyr ago eccentricity was large, but the transition to interglacial was very mild (Fig. 1). 
9) Why does termination II (approximately $135 \mathrm{kyr}$ ago) lead the rise in insolation?

Models proposed for the 100-kyr cycles generally divide into those models having self-sustained oscillations and models driven by external forcing, or into nonlinear and linear models (see the reviews by Imbrie et al. 1993; Elkibbi and Rial 2001). Suggested mechanisms include a nonlinear transfer of energy from the Milankovitch forcing at higher frequencies to the $100 \mathrm{kyr}$ (Le Treut and Ghil 1983), isostatic adjustments of the lithosphere under the weight of the glacier (Oerlemans 1982), slow $\mathrm{CO}_{2}$ feedback (Saltzman and Maasch 1988), thermohaline circulation feedbacks (Ghil et al. 1987; Broecker and Denton 1990) and interplanetary dust (Muller and McDonald 1995).

\section{b. Multiple equilibria and thresholds}

Paillard (1998) suggested a very "pure" conceptual model, one with virtually no commitment to specific physical processes. Its high degree of abstraction makes it especially illuminating. Milankovitch forcing is imposed on a glacial-interglacial cycling mechanism consisting of jumps between three modes of the climate system: interglacial $(i)$, mild glacial $(g)$, and full glacial $(G)$. Rules are specified for the transition between these modes:

- $i \rightarrow g$ (glaciation begins) occurs when the insolation decreases below a threshold $i_{0}$.

- $g \rightarrow G$ (glaciation approaching its maximum) occurs when the ice volume increases above some threshold value $V_{\max }$

- $G \rightarrow i$ (deglaciation) occurs when the insolation increases above some threshold $i_{1}>i_{0}$.

Parrenin and Paillard (2003) modified this model so that deglaciation occurs when a combination of insolation and ice volume is above a threshold. This modification improves the agreement between the model results and the climate records. The fit is very impressive, satisfying many of the above-mentioned observed characteristics of the glacial cycles (Fig. 1). Still, this model does not explain the actual physical mechanism or, say, what components of the climate system are responsible for the thresholds/multiple modes, etc., although a few hypotheses exist (Paillard 2001, 1998). This simple model implies that thresholds, a feature common to most of the low-order glacial-interglacial models, are essential elements of any glacial cycling mechanism. In the next section we give an example of a recent model of this kind that is fleshed out with explicit (though schematic) physical mechanisms.

\section{c. A sea ice switch model}

The importance of sea ice in the climate system has long been recognized (e.g., Saltzman and Moritz 1980). Sea ice presence and evolution affect the surface albedo and the salinity budget in the ocean. By partially insulating the ocean from the atmosphere it also changes air-sea heat flux, $\mathrm{CO}_{2}$ flux, and evaporation. Nevertheless, most theories and simple models have no role for sea ice. Because of the strong seasonal cycle of sea ice, it was taken as a fast-response climatic variable that equilibrates with global temperature changes (Källén et al. 1979; Saltzman and Sutera 1984). Such a treatment does not allow for a transition between the different qualitative regimes of sea ice cover.

Gildor and Tziperman, (2000, 2001a,b) proposed a mechanism in which sea ice acts as a "switch" of the climate system, switching it from glaciation to deglaciation. It is based on the somewhat debated (Gildor 2003a,b; Alley 2003) "temperature-precipitation feedback" (Le Treut and Ghil 1983), in which the rate of snow accumulation over land ice sheets increases with temperature, outweighing the corresponding increase in ablation and melting. Via its strong cooling albedo effect, its insulation effect on local evaporation, and its role in diverting the storm track, the sea ice controls the atmosphere moisture fluxes and precipitation that enable land ice sheet growth. The rapid growth and melting of the sea ice allow the sea ice to switch the climate system rapidly from a growing ice sheet phase to a retreating ice sheet phase, shaping the oscillation's sawtooth structure.

Gildor and Tziperman use a global meridional box model (fully described in Gildor et al. 2002) composed of ocean, atmosphere, sea ice and land ice submodels, including active ocean biogeochemistry and variable atmospheric $\mathrm{CO}_{2}$. Consider the full oscillation between years 170000 and 70000 in Fig. 2. Starting from an interglacial, the ocean is ice free (Fig. 2b) and the atmospheric temperature (Fig. 2d) and oceanic temperatures in the northern box are rather mild. The amount of precipitation enabling ice sheet growth in the northern polar box exceeds the melting and calving terms (Fig. 2c, year 170 000), and therefore the ice sheet gradually grows. The northern box atmospheric temperature while relatively mild, is below freezing, enabling the glacier to grow. The spreading of the land ice sheet increases the albedo, and consequently the temperature of the atmosphere and of the ocean in the corresponding polar box decreases slowly with the growing glaciers (Fig. 2d). Eventually, around year 90000 , the sea surface temperature (SST) reaches the critical freezing temperature, and sea ice (Fig. 2b) starts 

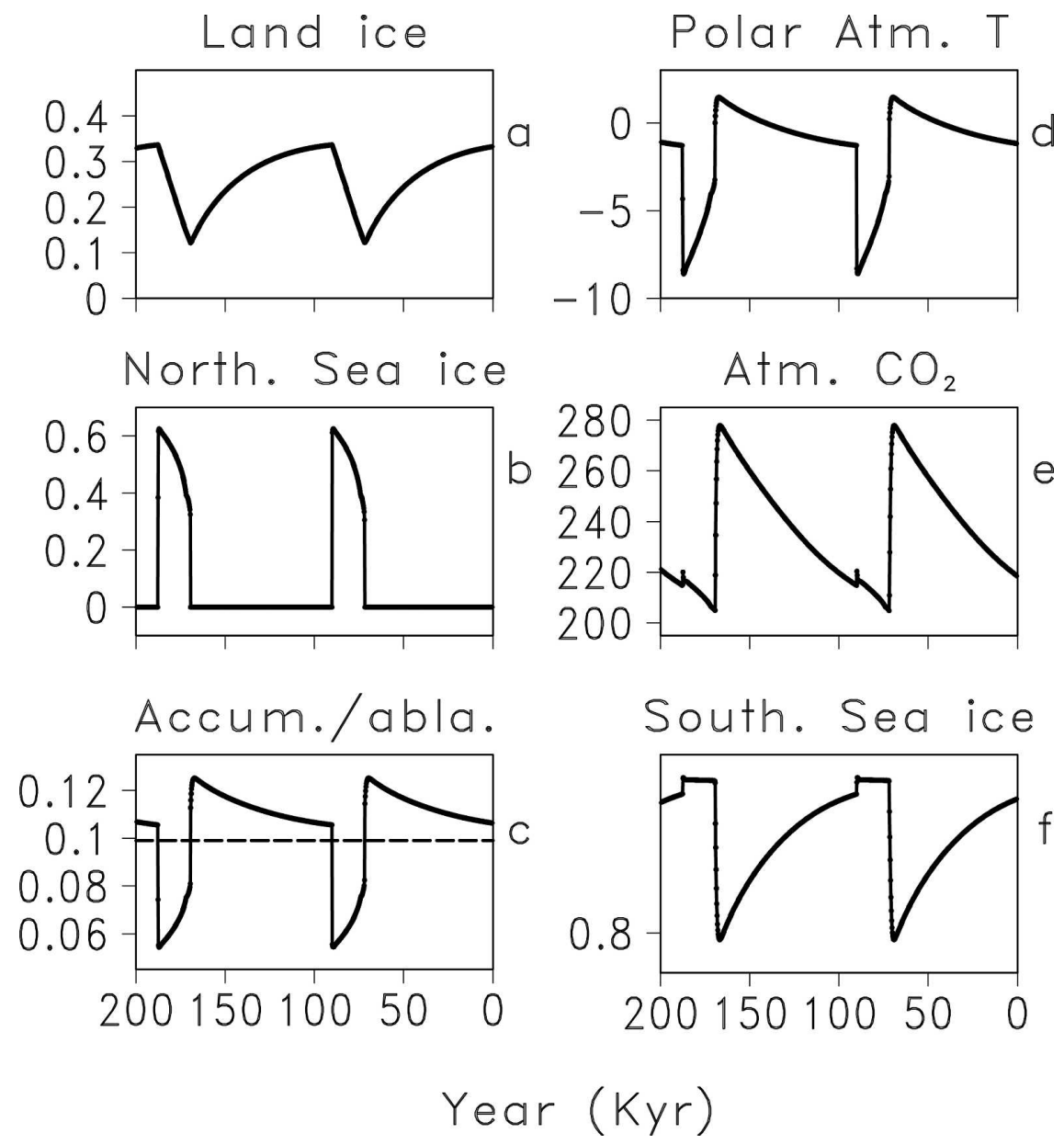

FIG. 2. Low-order sea ice switch model result time series for $200 \mathrm{kyr}$ with no orbital variations. (a) Northern land ice extent as a fraction of the polar land box area; (b) northern sea ice extent as a fraction of polar ocean box area; (c) source term (solid line) and sink term (dashed line), for northern land glacier $\left(\mathrm{Sv}, 1 \mathrm{~Sv} \equiv 10^{6} \mathrm{~m}^{3} \mathrm{~s}^{-1}\right)$; (d) northern atmospheric temperature $\left({ }^{\circ} \mathrm{C}\right)$; (e) atmospheric $\mathrm{CO}_{2}$ (ppm); and (f) southern sea ice extent as a fraction of polar ocean box area. Time is in "before present" model years, although no correspondence to actual time before present is meant; such correspondence is relevant only when Milankovitch forcing is included, and the results shown here were obtained when orbital parameters were held at their present values. (After Gildor et al. 2002.)

to form very rapidly. The creation of sea ice further increases the albedo, reduces the atmospheric temperature, and enhances the creation of more sea ice. The characteristic time scale of sea ice growth is very short, and in less than $50 \mathrm{yr}$ nearly the entire polar box ocean surface is covered by sea ice. The sea ice switch is now turned to "on."

At this stage, the average global temperature is at its lowest point, sea ice and land ice sheet extents are maximal, and the system is at a glacial maximum. Because of the low polar box atmospheric temperature (Fig. 2d, year 85 000), poleward moisture flux declines to about half its maximum value. In addition, the sea ice cover limits the moisture extraction by evaporation from the polar ocean box and further reduces the corresponding snow accumulation over the land ice. Being less sensitive to temperature than precipitation, ablation and glacier runoff dominate, so the glaciers start retreating. The land albedo decreases and the atmospheric temperature rises slowly. This is the beginning of the termination stage of the glacial period. The upper ocean in the polar box is at the freezing temperature as long as sea ice is present. However, once the deep ocean warms enough to allow the upper ocean to warm as well, the sea ice melts within $\sim 40 \mathrm{yr}$. [A similar rapid retreat of sea ice may have occurred at the end of the Younger Dryas (Dansgaard et al. 1989).] The sea ice switch is now turned to "off," the temperature of both 
the atmosphere and the ocean are at their maximum values, and the system is at an interglacial state, having completed a full glacial cycle. The cycle in glacier volume is equivalent to about $100 \mathrm{~m}$ of sea level change.

While not the direct forcing of the 100-kyr oscillations in this mechanism, Milankovitch forcing affects the characteristics of the 100-kyr cycle through nonlinear phase locking (Saltzman et al. 1984; Imbrie et al. 1993). When the model is forced with ablation as a function of summer insolation at $65^{\circ} \mathrm{N}$, runs with different initial conditions for the northern polar ice sheet extent all converge into a single time series after about 130 kyr (Gildor and Tziperman 2000). Milankovitch forcing is the pacemaker for the glacial cycles.

While the model used to demonstrate the sea ice switch mechanism is fairly idealized, its representation of the various climate components is sufficiently explicit for it to make predictions that can be tested with fuller GCMs and possibly with analysis of proxy records of sea ice as these become available. The main prediction of this model is the hysteresis of land ice and sea ice, namely different states of sea ice cover for advancing and retreating sea ice (Sayag et al. 2004). This model also predicts that the onset of the land deglaciation should correspond to a larger sea ice cover, and hence a colder period, and that extensive sea ice cover exists well into deglaciation. Hence there is no simple relationship between ice volume and temperature (cf. Paillard 2001).

\section{d. Stochastic models}

Generally, natural time series may be described by a set of dynamical equations with both deterministic and stochastic elements. The extent to which climatic record can be explained by the Milankovitch theory is still controversial. For example, Paillard (2001) suggests that the climate system is mainly deterministic on the glacial-interglacial time scale, while Wunsch (2003) suggests that Milankovitch forcing can explain only a small fraction of the variability.

Wunsch (2003) demonstrates that it is possible to replicate a realistic-looking time series for ice volume by a simple stochastic model that includes a threshold. In the Wunsch model, ice volume $V(t)$ builds up randomly to a specified maximal threshold at which point it breaks up rapidly. Then, growth begins again. The ice volume thus fluctuates between the maximal threshold and zero, and the ice volume growth is similar to a simple linear random walk. Note that this model relies on thresholds and is nonlinear. Ashkenazy et al. (2005) suggest models with both deterministic and stochastic elements, which account for some of the stochastic nonlinear features of ice core (Ashkenazy et al. 2003).
Benzi et al. (1982) suggested stochastic resonance as a mechanism for glacial cycles. Stochastic resonance may occur in a system with two stable equilibria (e.g., a cold glacial state and a warm interglacial state) separated by a threshold. The system is driven by both random noise and by slow and small-amplitude periodic oscillations due to Milankovitch forcing. The periodic force by itself cannot drive the system above the threshold, but the right combination of noise amplitude and periodic forcing can cause a transition. Because this mechanism is expected to produce symmetric oscillations, it is probably not the main reason behind the 100-kyr cycle (Tziperman 2001; Pelletier 2003).

Pelletier (2003) suggested a simple model based on coherence resonance to explain the glacial-interglacial cycles. As in stochastic resonance, there is a system with two stable equilibria separated by a threshold, but unlike stochastic resonance, coherence resonance relies on the nonlinear dynamics of the system rather than an external periodic forcing. It requires a delayed feedback in the system, that is, a forcing that depends on the state of the system at a previous time (Tsimring and Pikovsky 2001; Pelletier 2003). In the model of Pelletier, isostatic adjustment of the lithosphere provides the delayed feedback. In coherence resonance, occasionally the noise drives the system enough in the same direction to cross the threshold. The chance for this to occur depends on the time scale of the delayed feedback and the level of noise. This model reproduces the saw-tooth structure of the climate record and the 100-kyr time scale. Timmermann et al. (2003) present an alternate coherence resonance scenario.

\section{e. Discussion: Low-order models}

Many low-order models fit the global ice volume proxy curves quite impressively, perhaps not a surprise considering the number of tunable coefficients in them (Tziperman 2001; Roe and Allen 1999) and uncertainties in the data. It seems likely that any model that has a free nonlinear oscillation at about the 100-kyr period and that is forced by Milankovitch forcing will be phase locked to the forcing and will result in a good fit to the global ice volume proxy curves. Obviously models driven by Milankovitch forcing will show coherence with the data. Phasing between the hemispheres and between climate parameters (as temperature and ice volume) is ambiguous, partly due to millennial-scale variability superimposed on the glacial cycle signal (Alley et al. 2002), partly because each proxy for ice volume (like $\delta^{18} \mathrm{O}$ from planktonic and benthic foraminifera) is also affected by other factors (such as temperature, salinity, and pH; e.g., Mix et al. 2001), and partly because the data may be biased by seasonality of 
the specific proxy (Gildor and Ghil 2002). In addition, phasing between climate variables such as ice volume and temperature may change in time, making it difficult to distinguish between cause and effect (Karner and Muller 2000). There is a need to develop ways to distinguish between competing explanations that all fit a few data time series; the models must make new and independent testable predictions. Despite major advances in the last few decades, the increasing number of models for the ice ages in recent years is evidence that we still lack a satisfying explanation of the dynamics of the large-amplitude glacial climate cycles.

\section{Glacial inception}

\section{a. Phenomenology}

The last glacial inception has been the focus of many modeling studies primarily because it is the one best documented by proxy data and thus provides precious information concerning the environmental changes that lead to glaciation. The preceding interglacial, the Eemian, is the last interval in which the global climate was close to that of the present day. The correlative marine isotope substage (MIS) 5e, as recorded by the marine oxygen isotopic composition, shows that this period of minimum ice volume lasted some $12000 \mathrm{yr}$ starting at about $128000 \mathrm{yr}$ before present (128 kyr B.P.). At the late boundary of the Eemian, $116 \mathrm{kyr}$ B.P. (the MIS $5 \mathrm{e} / 5 \mathrm{~d}$ transition in ocean records), the climate started to cool down, marking the beginning of the most recent glacial stage (Shackleton et al. 2002; Chapman and Shackleton 1999). Coral reef and marine oxygen isotopic records from different regions in the world indicate a global sea level drop of between 2 and $7 \mathrm{~m}$ over $1 \mathrm{kyr}$ during the early stage of the interglacial-glacial transition (Lambeck and Chappell 2001; Shackleton 1987), but little is known of the location of the initial water storage in ice sheets that ultimately grew to cover North America (the Laurentide ice sheet) and northern Europe (the Fennoscandian ice sheet).

\section{b. Past theories and models}

The last transition to a glacial climate was at a time when northern high-latitude summer insolation was at a minimum, in accord with the Milankovitch theory (section 2a). The earliest attempts to test this theory involved simple conceptual models that tried to reproduce ice age cycles driven only by summer insolation changes at $65^{\circ} \mathrm{N}$, the latitude near a glaciation threshold according to Milankovitch (e.g., Imbrie and Imbrie 1980). Experiments with two-dimensional energy balance models (EBMs) coupled to an ice sheet model and/or a mixed layer ocean have had some success in reproducing the major characteristics of glacialinterglacial cycles, but only by applying reconstructed atmospheric $\mathrm{CO}_{2}$ variations in addition to the cycles of insolation forcing (Tarasov and Peltier 1997, 1999). Initial experiments with atmospheric general circulation models (AGCMs) consisted of changing the orbital parameters to their $116 \mathrm{kyr}$ B.P. values while assigning present-day values to vegetation, ocean temperatures, and sea ice. The climatic adjustment was analyzed in terms of cooling and snowfall distributions. The results were disappointing: changing only solar insolation failed to produce perennial snow. How snowmelt is parameterized and the impact of the model resolution on the effect of altitude on snow nucleation, as well as the bias in the simulated present-day climate, are all reasons that might explain the difficulties encountered by GCMs in reproducing glacial inception (Vettoretti and Peltier 2003). However, with the substantial increase in the number of proxy and modeling studies of the last glacial inception during the last decade, it has been concluded that most of these experiments had two major weaknesses. First, the atmosphere did not cool the climate enough to prevent snow from melting. Second, and most important, the cooling made the atmosphere drier, preventing any increase in snowfall.

In the 1990s, new evidence of important vegetation changes over northern Canada and Europe at the end of the last interglacial (e.g., Pons et al. 1992) led to the idea that the recurring difficulties with most of these GCM studies were not only due to their biases, but might be linked to missing climatic feedbacks. Gallimore and Kutzbach (1996) performed sensitivity experiments in which boreal forests were replaced by tundra, while DeNoblet et al. (1996) used an AGCM asynchronously coupled to a vegetation model. With such changes prescribed, the increased land surface albedo helps to maintain snow cover over more than a seasonal cycle. Other experiments explored alternative feedbacks that may help to maintain perennial snow cover. The earliest simulations using an AGCM assumed that the sea surface temperatures were very similar to present day. To account for insolation changes on SST, Dong and Valdes (1995) coupled an AGCM to a mixed layer ocean and found that the ocean surface cools and sea ice cover expands. More importantly, the model delivered perennial snow cover over regions known to be the starting point of the ice sheets. This experiment was the first to reveal the role of the ocean in helping glacial inception. However, in light of recent data, the simulated summer cooling over high-latitude oceans of up to $8^{\circ} \mathrm{C}$ now appears unrealistic. Recent SST reconstructions show that the increased equator-to-pole in- 


\section{5 ky minus Control}

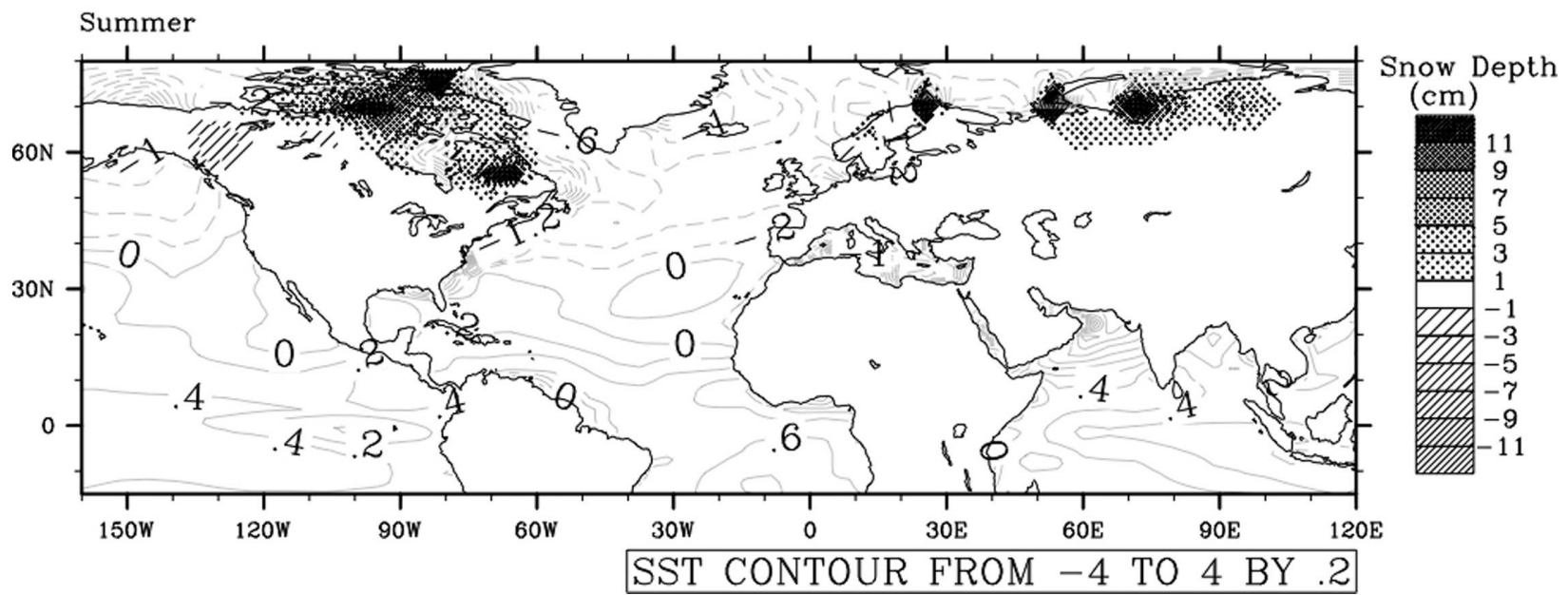

FIG. 3. Differences in simulated summer SSTs $\left({ }^{\circ} \mathrm{C}\right)$ and land snow depth $(\mathrm{cm})$ at the last glacial inception climate $(115 \mathrm{kyr}$ B.P. $)$ from those simulated for the present-day climate (Control). Results are from a coupled ocean-atmosphere general circulation model $(\mathrm{OAGCM})$ forced solely by orbital insolation changes. Values are between $\pm 3^{\circ} \mathrm{C}$ with $0.25^{\circ} \mathrm{C}$ contour intervals for SSTs, and between $\pm 13 \mathrm{~cm}$ with 2 -cm contour intervals for snow depth. The dotted (solid) isolines indicate a decrease (increase) in SSTs.

solation gradient around $115 \mathrm{kyr}$ B.P. creates a cooling of up to $3^{\circ}$ to $4^{\circ} \mathrm{C}$, at $72^{\circ} \mathrm{N}$ in the Norwegian Sea, while in the Atlantic Ocean low to mid latitudes remained warm even after the ice sheet started to build up (Cortijo et al. 1999; Chapman and Shackleton 1999; McManus et al. 2002; Shackleton et al. 2002).

\section{c. Coupled ocean-atmosphere results}

Model SSTs over the key North Atlantic region in the coupled atmosphere-ocean GCM (AOGCM) simulation of Khodri et al. (2001) are shown in Fig. 3. The geographical pattern of the data is generally reproduced: the high latitudes of the North Atlantic cool while the tropical and subtropical latitudes remain warmer, more similar to the present day. After several years, the $115 \mathrm{kyr}$ B.P. simulation produces perennial snow cover and then snow accumulation over the Canadian Archipelago (also see Fig. 4 of Khodri et al. 2001).

In this study the ocean translates the seasonal anomaly of insolation into an annual mean amplification of the equator-to-pole SST gradient. As a consequence, the low-latitude water vapor source increases and provides an increased moisture availability for the high-latitude atmosphere. The hydrological cycle change has major impacts on high-latitude climate. The annual mean increase of runoff into the Arctic Ocean induces an extension and deepening of the halocline, which, associated with the cooler surface water, increases Arctic sea ice volume and extent. This change in sea ice contributes to cooling of the land surrounding the Arctic Ocean, such as the Canadian Archipelago, by increasing local albedo. The increased freshwater input into the Arctic Ocean also induces a reduction of the sea surface salinity (SSS). Subsequently, the decreased meridional density gradient in the northern seas leads to a shift of the location of deep-water formation toward lower latitudes, which, in turn, inhibits the convergent transport of heat by the ocean to those latitudes now covered by sea ice. Finally, the amplified high-latitude cooling by these feedbacks translates the increased atmospheric water vapor transport into increased snowfall over regions where ice sheets can grow. Including the ocean feedback provides more moisture to northern high latitudes. This is the essential effect that allows snow to accumulate, triggering the "Milankovitch effect."

Earth Models of Intermediate Complexity (EMIC) include most of the components of the climate system, such as the ocean, biosphere/carbon cycle, sea ice, and ice sheets, but their representations are simplified so that several multimillennial transient simulations and sensitivity experiments can be performed without computing time restrictions. This is particularly important for the last interglacial-glacial transition since data show important transient changes. An "intra-Eemian" cooling around $122-120 \mathrm{kyr}$ B.P. is seen in both marine and continental data in several locations in Europe. A rapid shift to a colder climate and reduced sea surface salinity is recorded in high-latitude oceans during the 
second part of the last interglacial near $120 \mathrm{kyr}$ B.P. (Cortijo et al. 1999; Maslin et al. 2001; Oppo et al. 2001; Sànchez-Goñi et al. 1999; Tzedakis et al. 2002), an event followed by another cooling step marking the end of the last interglacial, around $115 \mathrm{kyr}$ B.P. (Chapman and Shackleton 1999; Shackleton et al. 2002).

Using an EMIC, Crucifix and Loutre (2002) showed that the gradual reduction of summer insolation from 126 to $115 \mathrm{kyr}$ B.P. induces a gradual expansion of the Arctic sea ice, hastening the southward shift of the northern tree line by $1000 \mathrm{yr}$ and allowing the accumulation of perennial snow cover over northern lands as early as $122 \mathrm{kyr}$ B.P. Wang and Mysak (2002) also reproduce glacial inception by coupling an EMIC to an ice sheet model. However, as in Crucifix and Loutre (2002), the reduced freshwater input to high-latitude oceans causes a gradual increase of SSS in the northern seas, whereas Cortijo et al. (1999) reported a freshening of the northern oceans from 122-120 kyr B.P. until 115 kyr B.P. Using a coupled ocean-atmosphere EMIC forced by insolation changes only, Khodri et al. (2003) also found that the SSS in the Northern Seas increased and that the model did not simulate perennial snow cover. However, when the northward atmospheric moisture transport was artificially amplified to mimic the AOGCM results, the EMIC was able to simulate the northern SSS decrease and perennial snow over northern Canada (Khodri et al. 2003).

Thus, a major finding of recent model studies of interglacial-glacial transition is the central role played by hydrological cycle changes. The increased northward moisture transport amplifies the high-latitude cooling initiated by the insolation change through an intricate network of feedbacks involving sea ice and the ocean, but it also moistens the atmosphere so snow delivery can increase.

\section{Results from the Paleoclimate Modeling Intercomparison Project}

\section{a. Overview}

The international Paleoclimate Modeling Intercomparison Project (PMIP 2000), was created to assess the ability of models to simulate climates very different from the present day. PMIP has stimulated data syntheses for two key periods in the past, the LGM (21 kyr B.P.) and the mid-Holocene (6 kyr B.P.; e.g., Harrison 2000). PMIP1, the first phase of PMIP, considered only AGCMs. The last years have seen an increasing number of coupled ocean-atmosphere and atmospherevegetation model paleoclimate studies, first for the mid-Holocene (see Braconnot et al. 2004), and more recently for the LGM (Hewitt et al. 2001; Kim et al.
2003; Kitoh et al. 2001; Shin et al. 2003a). Only a few simulations have incorporated both the ocean and vegetation feedback (Braconnot et al. 1999).

\section{b. The Last Glacial Maximum and the mid-Holocene}

At the LGM there were 3- to 4-km-high ice sheets spread over North America and Scandinavia and the concentration of carbon dioxide was reduced to about $200 \mathrm{ppm}$. The mean global cooling was about $5^{\circ} \mathrm{C}$. In PMIP1 the AGCMs were either forced by the CLIMAP (1981) reconstruction of SST or coupled to a simplified slab ocean model. In the coupled model experiments of PMIP2 only external conditions such as the $\mathrm{CO}_{2}$ level and the ice sheet location and topography need to be prescribed (see http://www-lsce.cea.fr/pmip for more information).

Results of PMIP simulations exhibit a global cooling of about $4^{\circ} \mathrm{C}$ when SSTs are prescribed and from $2^{\circ}$ to $6^{\circ} \mathrm{C}$ when SSTs are computed. The cooling is larger over land and ice-covered regions, because of the smaller thermal inertia of land and the large ice and snow albedo feedback (Fig. 4). The change in the latitudinal temperature gradient in the Atlantic Ocean together with the orographic effect of the ice sheet favors an eastward shift of the core of the storm-track activity (Kageyama et al. 1999). Most coupled ocean-atmosphere simulations provide a similar range for the global cooling (Hewitt et al. 2001; Kim et al. 2003; Kitoh et al. 2001; Shin et al. 2003a), though the simulated pattern of SST change varies greatly from one model to the other. For example, the Third Hadley Centre Coupled Ocean-Atmosphere GCM (HadCM3; Hewitt et al. 2001) simulation exhibits a warming in the North Atlantic not found in the National Center for Atmospheric Research (NCAR) Climate System Model (CSM; Shin et al. 2003a) coupled simulation (Fig. 5), apparently due to strong katabatic flow off the ice sheet, and a shift in the boundary of the subpolar gyre and the location of deep-water formation (Fig. 6). Generally, the coupled simulations are an improvement over the AGCM results of PMIP1, reproducing observations over land more accurately, and capturing the changes in the temperature gradient over the ocean (Kageyama et al. 2006). However, none of the available simulations sustains the cold conditions over Europe suggested from data or give a realistic representation of Atlantic SST and sea ice cover. A simulation with a high-resolution model yielded only a slight improvement (Jost et al. 2005).

In the tropical regions the LGM has a damped seasonal cycle. Since evaporation is reduced over the cold 


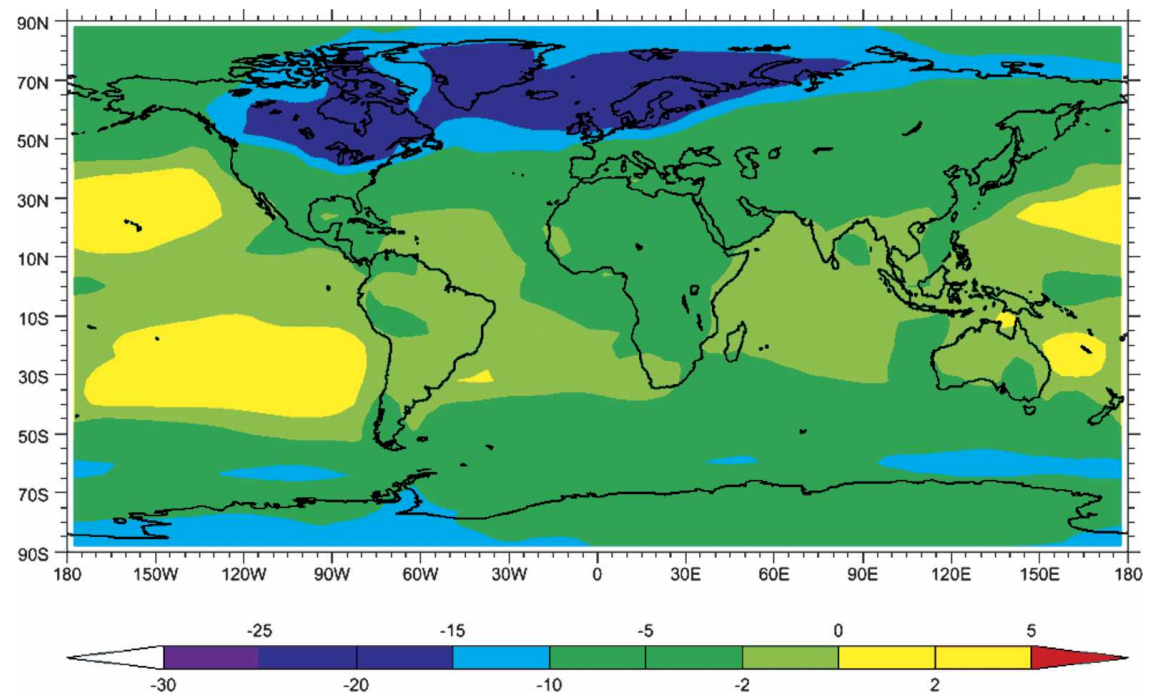

FIG. 4. Simulated change in annual mean surface temperature $\left({ }^{\circ} \mathrm{C}\right)$ at the LGM. Average of 9 PMIP1 simulations with SST prescribed according to the CLIMAP (1981) reconstruction. Isolines are plotted at every $5^{\circ} \mathrm{C}$, except that $\pm 2^{\circ} \mathrm{C}$ isolines are added to highlight temperature changes over the ocean. Data are from the PMIP database (http://www-lsce.cea.fr/pmip).

ocean, the LGM climate is more arid. Models with specified SSTs tend to underestimate the tropical land cooling, but some of the models that compute SST are consistent with data reconstructions (Pinot et al. 1999).

The difference in perihelion at mid-Holocene increased the incoming solar radiation at the top of the atmosphere about $5 \%$ in boreal summer compared to the present day. In response to the insolation forcing, the land-sea contrast responsible for the monsoon is enhanced in the Northern Hemisphere (NH). The intertropical convergence zone shifts to a more southward position over the ocean during winter and pen- etrates farther inland during summer. All PMIP simulations show that the summer monsoon flow brought more precipitation in now arid regions such as the Sahel region in Africa or the northern part of India (Fig. 7). Moisture advection plays a more important role in West Africa than local recycling, though local recycling does account for at least $30 \%$ of the precipitation in this region. None of the PMIP1 simulations change humidity in the Sahel region enough to allow the northward encroachment of steppe vegetation into the desert that is seen in the data (Harrison et al. 1998; Joussaume et al. 1999). The timing and the length of the monsoon

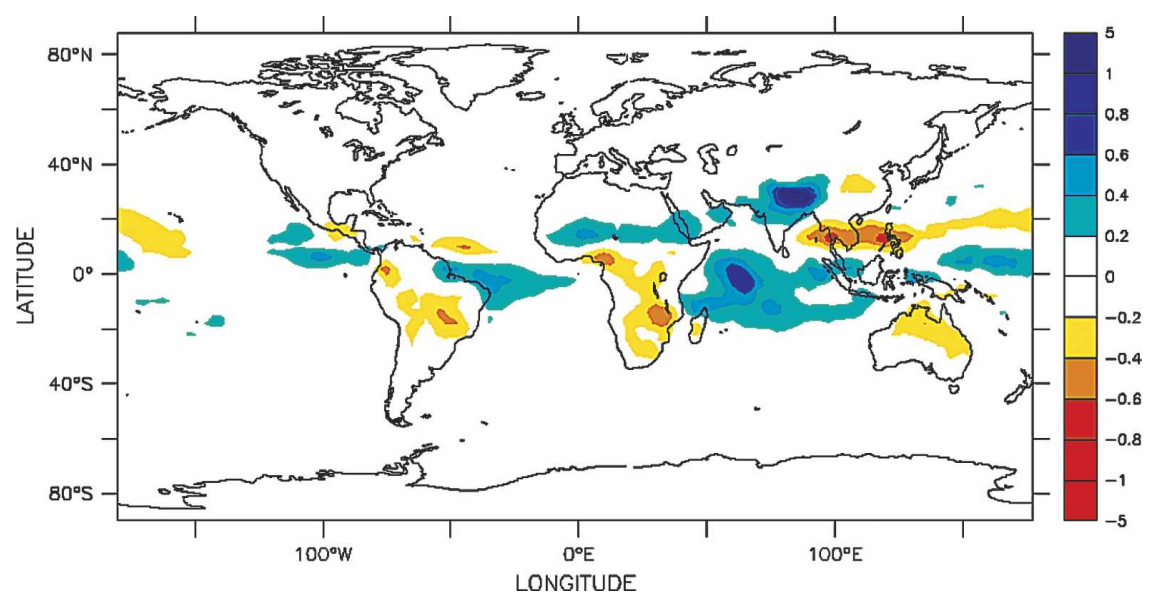

FIG. 5. Change in annual mean surface temperature, LGM - Modern, for two coupled simulations: (top) HadCM3 (Hewitt et al. 2001) and (bottom) NCAR CSM (Shin et al. 2003a). 

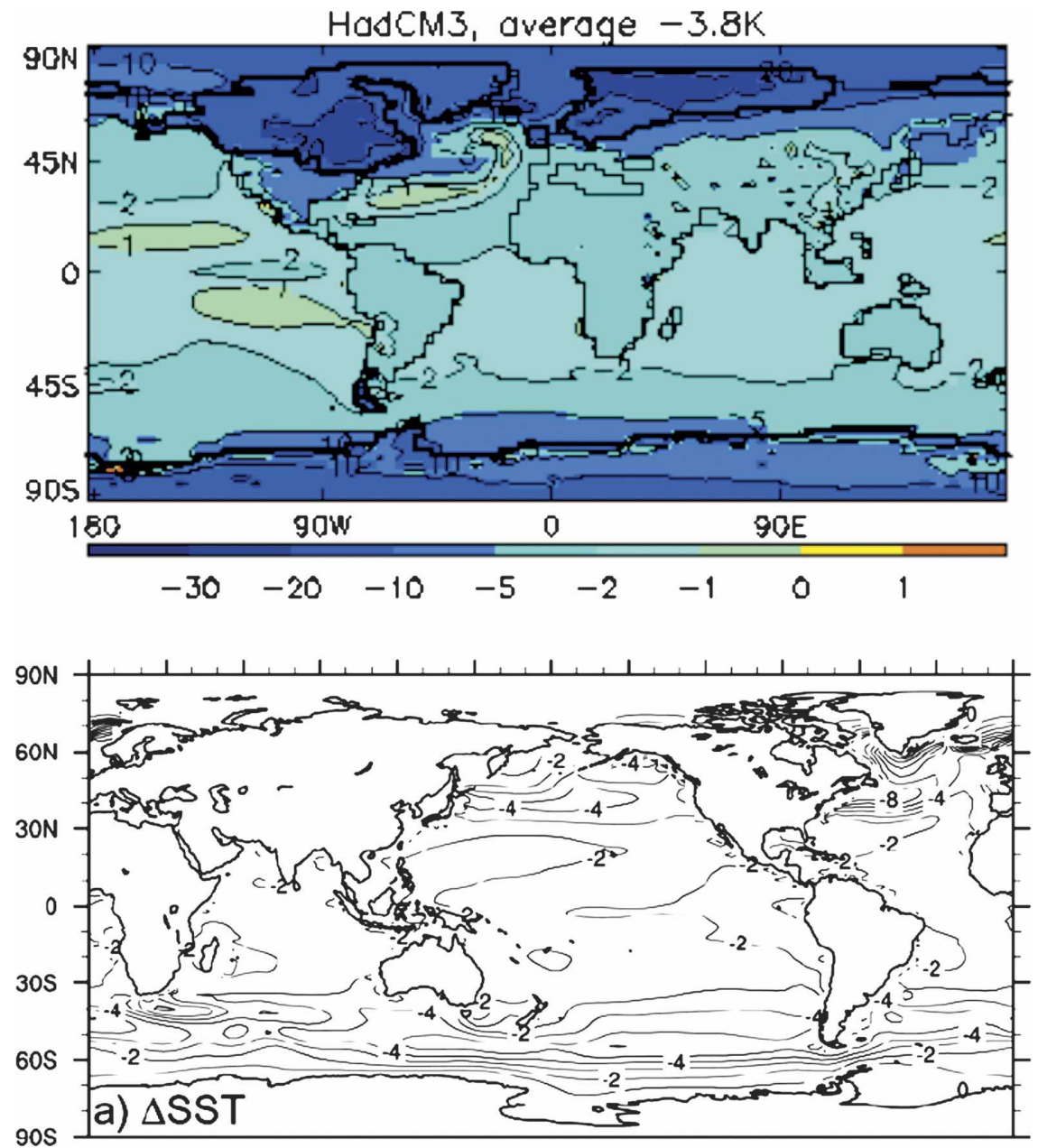

FIG. 6. Change in annual mean surface temperature, LGM-Modern, for two coupled simulations: (top) HadCM3 (Hewitt et al. 2001) and (bottom) NCAR CSM (Shin et al. 2003).

season is more consistent among the coupled simulations and the results are in better agreement with data (Braconnot et al. 2004).

\section{c. Ocean and vegetation feedbacks}

Simulated changes in SST and sea ice cover for the LGM are associated with changes in deep-water formation in the North Atlantic. Table 1 summarizes some recent results related to the thermohaline circulation. Most of these coupled simulations shift the deep-water formation in the North Atlantic southward and weaken the overturning circulation, as illustrated in Fig. 6. Most of the simulations also reinforce the formation of Antarctic Bottom Water. Shin et al. (2003b) show that the dominant mechanism is an increase of surface density due to brine rejection when sea ice forms. Results from intermediate-complexity models and stability studies suggest that during cold states the thermohaline circu- lation is close to a stability threshold (cf. section 5), and the different AOGCM results all appear to be plausible ocean states.

Coupled simulations of the mid-Holocene show little change in the overturning circulation. Analysis suggests that the buildup of a interhemispheric SST gradient across $5^{\circ} \mathrm{N}$ in the Atlantic feeds back on the strengthening of the African monsoon (Zhao et al. 2005). Also, the late warming of the northwest Indian Ocean in autumn delays the monsoon retreat in this region. This feature is maintained through a feedback loop between a reduction of the mixed layer depth and the input of low salinity water at the surface that both contribute to reduce the local inertia of the surface ocean (Zhao et al. 2005). Precession sensitivity experiments suggest that these features are the signature of late summer-fall insolation forcing during the mid-Holocene (Braconnot and Marti 2003). 

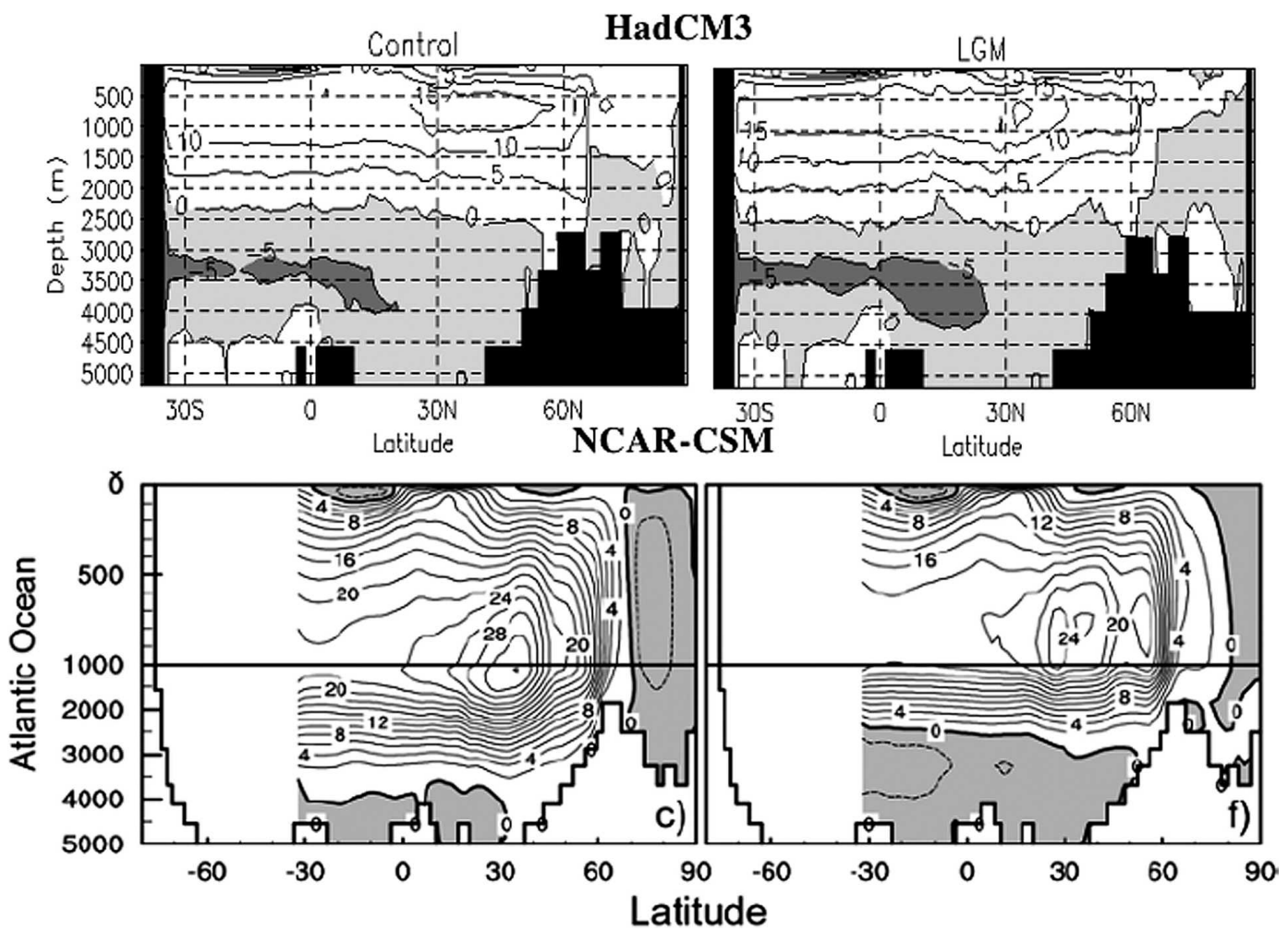

FIG. 7. Simulated change in boreal summer (Jun-Sep) precipitation $\left(\mathrm{mm} \mathrm{day}^{-1}\right)$ for the mid-Holocene, with an average of 18 PMIP1 simulations with fixed SST. Shading is blue in regions where precipitation is increased and red in dryer regions. Data are from the PMIP database (http://www-lsce.cea.fr/pmip).

Though changes in vegetation induce large feedbacks, they have less impact on the simulated climate than changes in the ocean circulation or in greenhouse gases. Shin et al. (2003a) estimated that changes in greenhouse gases account for half of the tropical cooling. Inclusion of the physiological effect of the $\mathrm{CO}_{2}$ concentration on vegetation is nonnegligible (Levis et al. 1999), impacting changes in the global forest (Harrison and Prentice 2003). Dust loading and deposition was larger during the LGM (e.g., Kohfeld and Harrison 2001), which has been attributed to changes in soil hydrology and vegetation cover (Mahowald et al. 1999).

The African monsoon in the mid-Holocene illustrates the synergy among the vegetation feedback, the ocean feedback, and the seasonal cycle of insolation (Braconnot et al. 1999). In response to the intensification of monsoon precipitation (Fig. 7) the desert steppe transition is shifted to the north. The ocean feedback

TABLE 1. Changes in LGM thermohaline circulation as inferred from various sources, including results from both EMICs and fully coupled OAGCMs.

\begin{tabular}{|c|c|c|c|c|}
\hline Authors & Model & $\Delta \mathrm{THC}$ strength (Sv) & $\begin{array}{l}\text { Convection } \\
\text { sites }\end{array}$ & $\begin{array}{c}\text { NADW } \\
\text { depth }\end{array}$ \\
\hline $\begin{array}{l}\text { Ganopolski et al. (1998; } \\
\text { Ganopolski and Rahmstorf 2001) }\end{array}$ & EMIC CLIMBER 2 & Weakening $(-4)$ & $60^{\circ} \mathrm{N} \rightarrow 50^{\circ} \mathrm{N}$ & Shallowing \\
\hline Wang et al. (2002) & EMIC atm EBM + 2D ocean & $\begin{array}{l}\text { Strengthening } \\
\quad(0-6 \text { depending on simulation })\end{array}$ & $75^{\circ} \mathrm{N} \rightarrow 60^{\circ} \mathrm{N}$ & Deepening \\
\hline Prange et al. (2002) & OGCM & Weakening $(-3)$ & $60^{\circ} \mathrm{N} \rightarrow 50^{\circ} \mathrm{N}$ & Shallowing \\
\hline Weaver et al. (1998) & $\mathrm{EMIC}$ atm $\mathrm{EBM}+\mathrm{OGCM}$ & Weakening & Same & Shallowing \\
\hline Schmittner et al. (2002) & $\mathrm{EMIC}$ atm EBM + OGCM & Weakening & Same & Shallowing \\
\hline Kitoh et al. (2001) & OAGCM & Strengthening & Same & Deepening \\
\hline Kim et al. (2003) & OAGCM & Collapse & & \\
\hline Shin et al. (2003a) & OAGCM & Weakening & $65^{\circ} \mathrm{N} \rightarrow 60^{\circ} \mathrm{N}$ & Shallowing \\
\hline Hewitt et al. (2001) & OAGCM & Strengthening & $65^{\circ} \mathrm{N} \rightarrow 35^{\circ} \mathrm{N}$ & Same \\
\hline
\end{tabular}




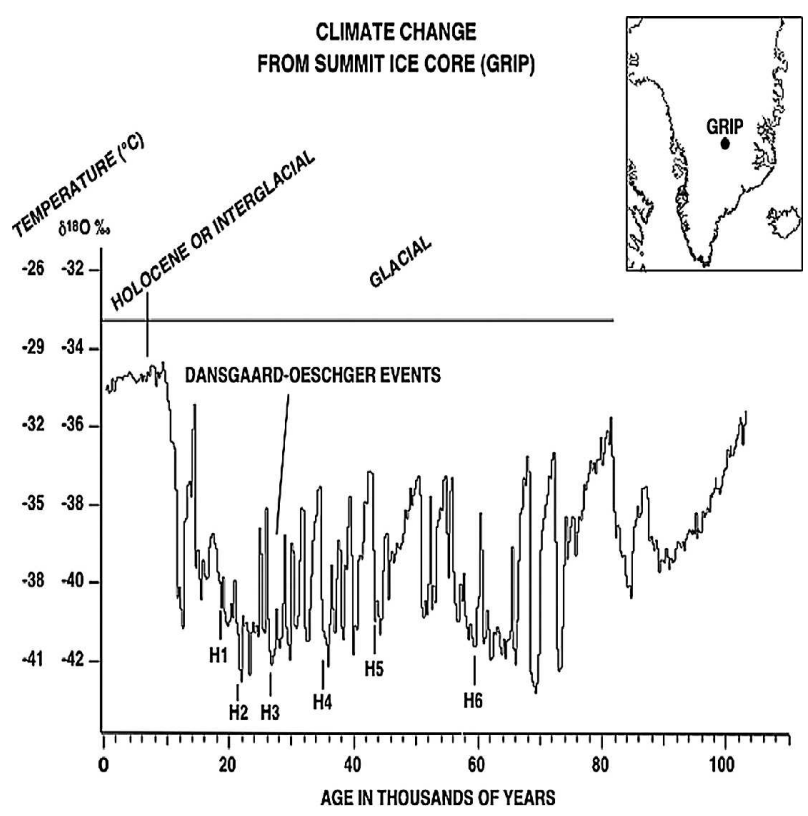

FIG. 8. Climate change record from the Greenland Ice Core Project (GRIP) ice core from the summit of Greenland, showing the Heinrich events (labeled H1-H6) and the millennial timescale Dansgaard-Oeschger events. The proxy plotted, $\delta^{18} \mathrm{O}$ is largely a function of temperature. The temperature scale on the left assumes that the isotopic signal is due entirely to temperature changes, which is only approximately true. (Figure courtesy of G. Bond.)

reinforces the inland advection of humidity, and as steppe replaces desert the albedo decreases and the surface warming in spring is enhanced. During the monsoon season, vegetation recycles soil moisture more efficiently than bare soil. This enhances the monsoon locally by latent heat release in the atmosphere when condensation occurs. The resulting change in precipitation is larger than the individual contributions from ocean or vegetation feedbacks alone. More generally, for the mid-Holocene Wohlfahrt et al. (2004) show that at middle and high latitudes the vegetation and ocean feedbacks enhance the warming in spring and autumn, respectively. Thus these feedbacks rectify the seasonal insolation forcing into a mean annual warming.

\section{Abrupt climate change during the last glacial period}

\section{a. Background}

The Dansgaard-Oeschger oscillations recorded in the Greenland ice cores (Fig. 8) look like "relaxation oscillations": they appear to be abrupt transitions, within decades, between warm and cold states of the system that last a millennium or longer. The evidence in
Greenland ice cores of annual mean temperature changes of the order of $10^{\circ} \mathrm{C}$ occurring in only a few decades (Fig. 8) implies massive climatic reorganizations in the North Atlantic region linked to changes in the thermohaline circulation. Freshwater inputs at high latitudes in the North Atlantic are often thought to be crucial. Freshwater fluxes at the ocean surface, and hence salinity fields, are largely decoupled from temperature fields, and thus provide additional degrees of freedom for the climate system. A large freshwater input in the high latitudes of the Atlantic can interfere with deep-water formation and drastically alter the thermohaline circulation. The possible changes are not limited to simple on and off modes but include a weakening of the circulation or shifts in the location of the convection areas where deep water forms. (Ganopolski and Rahmstorf 2001). The abrupt events of the last glacial period are probably linked to such oceanic switches. However, if they are triggered by freshwater perturbations, the origin of the freshwater is not yet accounted for. Some hypotheses invoke ice sheet instabilities, others coupled climate ice sheet oscillations, or even solar variability, as the source of these climatic oscillations. A satisfactory physical theory of abrupt climatic changes during glacial times still eludes us.

\section{b. Ice sheet instabilities and Heinrich events}

Heinrich events are characterized by massive inputs of ice rafted debris (IRD) in the North Atlantic between $40^{\circ}$ and $55^{\circ} \mathrm{N}$, transported by icebergs coming primarily from the Laurentide ice sheet. An associated massive freshwater input is unambiguously indicated by a light isotopic oxygen signal in the calcite of planktic foraminifera (Bond et al. 1993). It is natural to think that the melt water from such a large iceberg discharge affects the thermohaline circulation. The origin of such an event could lie in the dynamics of the ice sheet (MacAyeal 1993). Under the heating due to internal friction, basal friction, and geothermal flux, the ice sheet is warmer at its base and may be melting. Depending on basal rheology and hydrology, the melt water lubrication increases the ice velocity and could precipitate a massive iceberg discharge if the ice sheet is high enough to provide the necessary pressure. Favorable conditions for this mechanism could be available in the Hudson Bay beneath the Laurentide ice sheet; from there the icebergs could invade the Atlantic via the Labrador Sea. This scenario might account for the cycle of Heinrich events as follows (Paillard and Labeyrie 1994). 1) The ice sheet grows slowly, without iceberg discharges (>5000 yr). 2) An abrupt discharge follows from melting of the base of the ice sheet, which induces an iceberg flux able to interrupt the thermohaline cir- 
culation ( $<100$ yr). 3) The Heinrich event occurs and the iceberg flux and thermohaline shutdown continue ( 1000 yr). 4) The event ends: the ice sheet base refreezes, iceberg production stops, and the thermohaline circulation restarts $(<100 \mathrm{yr})$.

Available ocean surface temperature and salinity reconstructions (Cortijo et al. 1997) are compatible with a nearly complete shutdown of the thermohaline circulation (Paillard and Cortijo 1999). Furthermore, this scenario is simulated in a rather convincing way by some intermediate-complexity models (Calov et al. 2002), but it cannot be readily extended to the majority of abrupt climatic events recorded in Greenland (DansgaardOeschger events), which are not obviously associated with massive detrital inputs or large isotopic excursions in the North Atlantic. It would be necessary to invoke other iceberg sources, like Fennoscandia, since marine isotopic excursions associated with Dansgaard-Oeschger events are recorded in the Norwegian Sea. It remains to explain the characteristic succession of events recorded in Greenland (known as a Bond Cycle): Dansgaard-Oeschger events of decreasing duration, followed by an Heinrich event, followed by an abrupt warming reinitializing the whole sequence. DansgaardOeschger oscillations appear to have a preferred period of about $1500 \mathrm{yr}$ and may be very regular (Rahmstorf 2003). All these features are not easily compatible with several ice sheets of widely different sizes. Furthermore, these oscillations appeared soon after glacial inception, when ice sheets were a quite modest size. Weak versions even appear through the Holocene, the Little Ice Age being the most recent cold peak (Bond et al. 2001). It therefore seems as though any explanatory mechanism should not depend strongly on the size of the ice sheet.

\section{c. Ice sheet-climate oscillations}

Iceberg discharges do appear to occur during Heinrich events, but perhaps the other abrupt events involve different freshwater sources. At the beginning of the Holocene, about $8200 \mathrm{yr}$ ago, an abrupt cooling lasting less than a century has been recorded in many places. This event is coeval with the abrupt purge of the periglacial lakes Agassiz and Ojibway, at the southern margin of the Laurentide (Barber et al. 1999). The ice sheet was a dam for this lake. When it progressively retreated, it abruptly allowed for a rapid purge of the lake into the Atlantic Ocean, thus inducing a weakening of the thermohaline circulation and a few degrees cooling over the North Atlantic region. This scenario is well established for this 8200-yr event, and Clark et al. (2001) have suggested applying it to other events. This mechanism has the interesting feature of providing a self-sustained oscillator. If the cooling induced by the purge of the lake is large enough, it could allow a new progression of the ice sheet and the damming of a new lake. Freshwater would be accumulated instead of running toward the sea, allowing for a restart of the thermohaline circulation. This would warm high latitudes again and would favor the retreat of the ice sheet, thus closing the cycle. The time scale of such an oscillator would be the time required for the ice sheet to advance and retreat, of the order of a millennium, comparable to the time scale of Dansgaard-Oeschger oscillations.

In the conceptual model of Paillard (2004) the ice sheet-climate oscillation is based on the temperature dependence of the ice sheet surface mass balance. At very cold temperatures, there is only limited snow accumulation, and the mass balance is only slightly positive. At intermediate temperatures the water vapor content of the atmosphere is larger so accumulation can significantly increase. At warm temperatures melting will dominate and the mass balance will decrease rapidly with temperature. This temperature dependence is coupled to a bimodal climate system (warm state or cold state) with a two-mode thermohaline circulation. The resulting model has a simple self-sustained oscillation that switches climate from one mode to the other by alternatively transferring water between the ocean and the ice sheet.

Figure 9 illustrates another coupled climate-ice sheet oscillator based on the intermediate-complexity climate and biosphere (CLIMBER) model. Switching from an oceanic cold mode to a warmer state modifies the vertical structure of the atmosphere, which affects the balance between accumulation and ablation above the ice. Assuming no drastic change in the nature of the central Fennoscandian ice sheet, the downstream margins of the ice sheet should tend to a dynamical equilibrium that will be shifted by rapid climatic variations. The ice sheet evolution can be represented as $d z / d t=\left(z_{\max }-\right.$ $z) / \tau-M$, where $z$ is the height of the ice sheet margin, $M$ is the net surface melting (melting minus accumulation), $\tau$ is a dynamical time constant for glacier flow, and $z_{\max }$ is the height of the ice sheet margin in the absence of melting. For realistic values of $\mathrm{z}_{\max }$ and $\tau$, the dynamical term $D=\left(z_{\max }-z\right) / \tau$ falls between the cold and the warm state values of the net melting $M$ (Fig. 9a). At point 1 the thermohaline circulation is off (or, at least, low), and the climate is in a cold state, but the glacier is smaller than its equilibrium size. Hence the glacier grows toward point 2 where the absence of glacial melt water allows the thermohaline circulation to switch on. The climate now switches to a warm state (point 3) so melting increases and the glacier begins to shrink. Eventually (point 4), the glacial melt water 

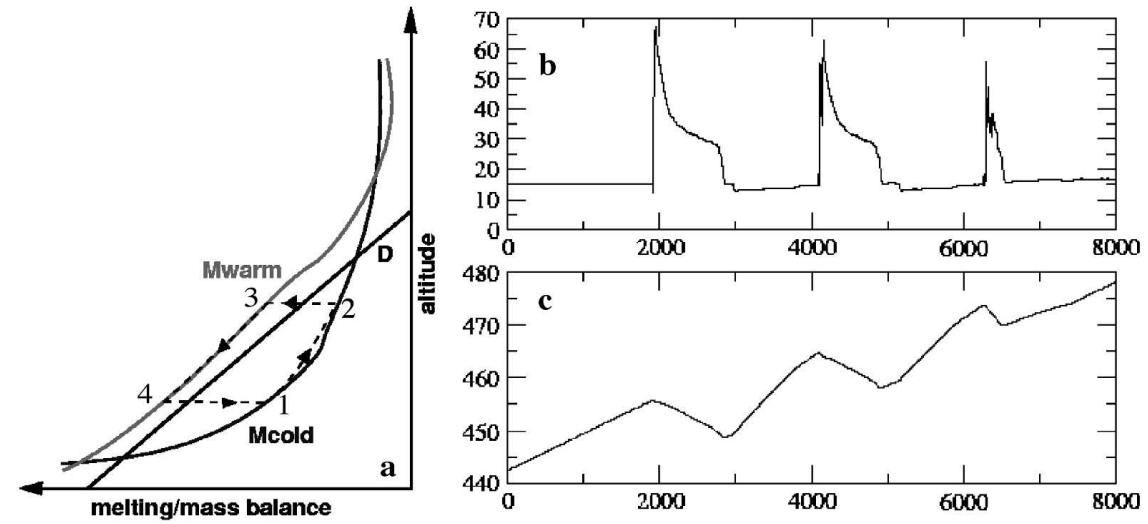

FIG. 9. (a) Terms in the dynamical balance of the Fennoscandian ice sheet margin. The curve D gives the dynamical mass balance term in the absence of melting. Mwarm (Mcold) is the melting rate in the warm (cold) climate state as a function of $z$, the height of the ice sheet margin. (b) When the ice sheet model is coupled to the intermediate-complexity CLIMBER climate model, the freshwater flux from the melting glacier to the ocean generates oscillations in the intensity of North Atlantic Deep Water (NADW; maximum of streamfunction, in Sv). (c) Evolution of the height of the Fennoscandian margin (m). Model time is in years. (From Kageyama and Paillard 2005.)

shuts down the thermohaline circulation, the climate flips back into a cold state, and the climate-ice sheet system is back at point 1 . The model oscillations (Figs. $9 \mathrm{~b}, \mathrm{c})$ share some interesting similarities with the Greenland data.

The concept of ice sheet-climate oscillators is very attractive, but the characteristics of the oscillation again depend strongly on the size of the ice sheet. Such an oscillator cannot work in the absence of the Laurentide and Fenoscandian ice sheets, which is problematic in view of data indicating the persistence of an oscillatory mode throughout the glacial period, and possibly even during the Holocene (e.g., Bond et al. 2001).

The persistence of a rather regular periodicity (Rahmstorf 2003) is an argument in favor of some possible external forcing, like solar variability (Bond et al. 2001). This is not necessarily in conflict with mechanisms like the ones listed above. If the objective is to synchronize oscillations loosely near a $1500-y r$ period or a multiple of it, then some weak external forcing together with some large internal variability may serve; for instance, through stochastic resonance (Ganopolski and Rahmstorf 2002). This last hypothesis has the potential to explain why a stable periodicity could appear even in presence of a wide range of past ice sheet sizes. But the data that could validate such a scenario are still elusive, and the physical mechanisms linking solar variability to large climatic consequences are speculative.

\section{d. Ideas from farther south}

The rapid overview we have given of different possible theories of abrupt climatic variability, though not exhaustive, represents the major tendencies followed in recent years to explain glacial oscillations. All these mechanisms involve some changes in the Atlantic thermohaline circulation, usually induced by changes in the hydrological budget of the high-latitude North Atlantic. But freshwater perturbations have been suggested at other places. A modification of the water vapor transport at low latitudes from the Atlantic to the Pacific (Cane 1998) or large freshwater perturbations from the Antarctic ice sheet (Weaver et al. 2003) are other possibilities. It must be emphasized that, for many reasons, paleoceanographic data are more numerous and usually easier to interpret in the North Atlantic. This has certainly induced a biased view of these past events, and the lack of numerous, well-preserved, highresolution data from the Southern Ocean does not prove that nothing happened there. Indeed, the formation of bottom waters around Antarctica is probably as important for the thermohaline circulation as are the deep waters from the North Atlantic, and there is no intrinsic reason to believe that abrupt changes should only occur in the north. Though available model simulations of thermohaline circulation changes induced in the North Atlantic do share many features with the available data (e.g., Ganopolski and Rahmstorf 2001), it is still difficult to explain the rapid connections observed between the different ocean basins, in particular in intermediate waters: in the Atlantic (Peterson et al. 2000), in the Arabian Sea (Schulz et al. 1998), or in the Pacific (Kennett et al. 2000). It is not clear how a change in the North Atlantic alone would affect these different basins. Since the Southern Ocean is more "at 
the center" of the world oceans, it is tempting to implicate it in the Dansgaard-Oeschger events. Some new ideas on the role of Antarctica on the glacial ocean circulation and on glacial climatic variability are very promising (Keeling and Stephens 2001).

\section{Paleo-ENSO modeling}

\section{a. Background}

Much is known about the seasonal and interannual time-scale behavior of ENSO, but much less is known about its long-term variability. Some unusual behavior in the 1990s along with the fact that the two largest events in the instrumental record occurred toward the end of the twentieth century (1982-83: 1997-98) sparked debate as to whether ENSO is being influenced by increasing levels of greenhouse gases (Trenberth and Hoar 1996; Rajagopalan et al. 1997). Looking back over the entire instrumental record, it is apparent that no two decades of ENSO variability have been the same, making it difficult to characterize the "natural" variability against which to test whether there is an anthropogenic influence.

Some aspects of these issues can be addressed by looking into ENSO's past. A wide range of proxies are now available that extend the record back in time to better characterize the inherent variability of ENSO. These data can also provide information about the behavior of ENSO when the external forcing and mean climatic state were different from today, covering periods from the last millennium to $130 \mathrm{kyr}$ B.P. Ideally, we could "validate" current models of ENSO by running them under specific climatic conditions for those times in the past and then comparing results with the available data. ENSO is a coupled phenomenon, so it is necessary to represent atmospheric and ocean physics on a wide range of temporal and spatial scales. For example, convective events in the atmosphere that communicate the influence of the surface conditions deep into the tropical troposphere occur on time scales of days and spatial scales of tens of kilometers. On the other hand, the adjustment of the thermal structure of the equatorial thermocline involves the meridional overturning ocean circulation, which extends into the subtropics (Fine et al. 1987; Gu and Philander 1997; Liu et al. 1994; Lu and McCreary 1995; Rodgers et al. 1999) and, some argue, involves higher-latitude water masses (Liu et al. 2002; Rodgers et al. 2003). The time scales of these physical processes range from months to centuries.

Coupled general circulation models (AOGCMs) have a relatively complete set of ocean and atmosphere physics, but unfortunately very few of the current gen- eration of AOGCMs simulate ENSO realistically (Latif and ENSIP Group 2001; AchutaRao and Sperber 2002). They are also computationally expensive, making it difficult to run simulations well matched to paleoclimate time scales. In intermediate coupled models, such as that of Zebiak and Cane (1987), anomalies are computed about a specified mean state and the physics are stripped down to the minimum needed to simulate ENSO. The duration of model simulations is essentially unlimited, permitting many sensitivity experiments. However, this type of model omits physics that is likely to be important on the time scales of interest (such as the thermal adjustment of the equatorial thermocline), and interpretation of the results is difficult for periods in the past when the mean climate was much different from today.

\section{b. The mid-Holocene}

The period for which the most consistent picture has emerged from modeling and data studies is the postglacial period dating from about 15000 B.P. to the present, with especially good coverage in the mid-Holocene. The data available for this time period include archaeological middens (Sandweiss et al. 2001, 1996), fossil corals (Gagan et al. 1998; Rodbell et al. 1999; Tudhope et al. 2001), lake sediments (Moy et al. 2002; Rittenour et al. 2000; Rodbell et al. 1999), ocean sediments (Haug et al. 2001), and pollen records (McGlone et al. 1992; Shulmeister and Lees 1995). While the data sources are quite varied, they all tell a consistent story: ENSO variability was weaker prior to 5000 B.P. than it is today. Some of these studies also seem to suggest that ENSO variability peaked in strength around 3000-1000 B.P. and has been decreasing since (Moy et al. 2002; Sandweiss et al. 2001). Some previous studies interpreted the data as indicating that the tropical Pacific locked into a permanent El Niño-like state (i.e., a warm eastern equatorial Pacific) with no ENSO variability. Others took the view that the ENSO cycle weakened during this period but did not cease. Most of these also believed that the eastern Pacific was colder than in the modern era (i.e., more La Niña-like).

The orbital forcing over this period is dominated by the precession of the equinoxes through the year. Currently, perihelion occurs in January. At about 11000 B.P. perihelion occurred in July so there was an increase in the incident solar radiation during boreal summer. Clement et al. (2000) imposed the orbital forcing of the last $15000 \mathrm{yr}$ on the Zebiak-Cane model and showed that an additional heating at this time of year produces a deeper low in the western Pacific, a region of mean convergence and ascent in the atmosphere, than in the east, a region of atmospheric subsidence, and the re- 


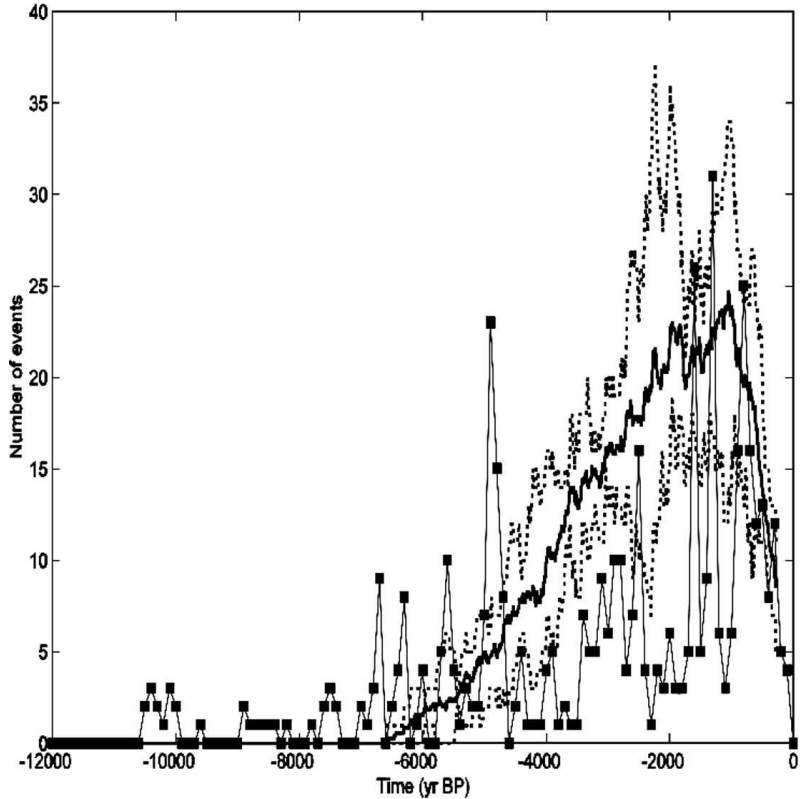

FIG. 10. Number of warm ENSO events in 100-yr windows. The black line with squares is proxy data from a lake in Ecuador (Moy et al. 2002). Warm ENSO events are defined as light colored strata in the sediment record, which reflect pluvial episodes during large El Niño (warm) events. The solid line shows the ensemble mean of seven simulations with the Zebiak-Cane model forced by the orbital variations of the last $12000 \mathrm{yr}$. The dotted lines show the min and max values over the ensemble. Warm ENSO events are defined in the model as years in which the December-February (DJF) SST anomaly in the Niño-3 region $\left(5^{\circ} \mathrm{N}-5^{\circ} \mathrm{S}, 90^{\circ}-150^{\circ} \mathrm{W}\right)$ exceeds $3^{\circ} \mathrm{C}$. This event index corresponds to the middle of the rainy season in coastal South America during which large SST anomalies associated with ENSO events are capable of causing the ITCZ to move equatorward and bring large precipitation anomalies to the region.

sultant pressure gradient causes an increase in the strength of the trade winds. The anomalous trade winds set off a positive feedback between the ocean and atmosphere that amplifies the signal, the same feedback that Bjerknes $(1966,1969)$ invoked to explain the growth of ENSO events. This "Bjerknes feedback" leads to a cooling in the eastern equatorial Pacific in the boreal fall, the season in which ENSO events have the highest growth rates (Zebiak and Cane 1987). The overall effect is to dampen the growth of warm events during that season, and as a result the number of warm events was significantly lower at 11000 B.P. and gradually increased over the Holocene.

In Fig. 10 the results from the model are compared with a proxy record of ENSO from an Ecuadorian lake published by Moy et al. (2002). The proxy for ENSO is the clastic sediment washed into the lake during the heavy rains that occur almost exclusively during large El Niño events. Because the clastic sediments are so much lighter in color than the organic material depos- ited the rest of the time, it is possible to count "events." Figure 10 shows the number of events in $100-\mathrm{yr}$ windows in both model and data. Model warm events are defined as years in which the December-February mean Niño-3 index exceeds $3^{\circ} \mathrm{C}$. This event index corresponds to the middle of the rainy season in coastal South America, when SST anomalies associated with large ENSO events move the ITCZ equatorward and bring large precipitation anomalies to Ecuador and Peru. An ensemble of seven experiments was performed to better determine which aspects of the ENSO behavior are related to the forcing and which to internal variability. The agreement between the model and data implies that both the increase in number of warm events over the Holocene as well as the peak around 1000 B.P. can be explained solely by tropical Pacific coupled interactions in response to orbital forcing. Clement et al. (2000) found that the mean state change in the mid-Holocene was small but La Niña-like in that temperatures in the equatorial eastern Pacific cooled by more than those in the west.

There is a large degree of suborbital time-scale variability in both the model and data. The ensemble shows that some fraction of this can be explained by variability internal to the tropical Pacific (since the model is confined to that region). However, the data variance exceeds that of the ensemble. This may be an artifact of the data recorder; it is plausible that the flux of clastic sediment due to precipitation changes has greater variance than Niño-3 SST. Another possibility is that other climate forcings, not accounted for in the model experiment, affect ENSO behavior over the Holocene. Solar irradiance, for example, varies on time scales of decades to centuries (Crowley 2000), and Mann et al. (2004) have shown that ENSO behavior is sensitive to even small irradiance changes.

There are several studies with AOGCMs that corroborate the results of the intermediate model. Experiments have been done in which the orbital configuration was set to either 6, 9, or $11 \mathrm{kyr}$ B.P. (Kitoh and Murakami 2002; Liu et al. 2000; Otto-Bliesner et al. 2003), times in which the boreal summer insolation was stronger than today. All show that the mean state change is small and La Niña-like. Otto-Bliesner (1999) and Liu et al. (2000) find that ENSO variability (as measured by the variance of the eastern equatorial $\mathrm{Pa}$ cific SST) was weaker than that of modern day. The Bjerknes feedback is again fundamental to the results. In the AOGCMs, the additional solar heating in the mid-Holocene boreal summer strengthened the Asian monsoon, increasing the trade winds in the Pacific. The Bjerknes feedback, operating in the same way in the AOGCMs as in the simpler Zebiak-Cane model, 
dampens the growth of warm events resulting in weaker variability. Thus the models are telling a consistent story, one consistent with the data as well: observed weaker variability of ENSO in the mid-Holocene is a response to orbitally driven changes in the seasonal cycle.

\section{c. Glacial periods}

The results for the mid-Holocene suggest that we have a fairly good understanding of how changes to the seasonal cycle influence ENSO variability. However, success appears to be limited to times when the annual mean climate state is roughly the same as today. Simulations of the Last Glacial Maximum, a time when the entire globe was several degrees colder, have now been done with a few different AOGCMs, and results are not consistent: the Hadley Centre model experiment (Hewitt et al. 2001) shows no change in ENSO variability (C. Hewitt 2004, personal communication), while the NCAR coupled model experiment shows stronger variability (Otto-Bliesner et al. 2003). There are not enough ENSO proxy data at the LGM to tell us what the right answer is. The few short records available at other glacial times do not agree well with simulations with the Zebiak-Cane model forced solely by orbital forcing (Tudhope et al. 2001). While the records are too short to allow firm conclusions, the indication is that glacial era changes in the mean state have a substantial impact on the ENSO cycle. This raises questions about the applicability of what we can learn from the past to the future of ENSO under increasing greenhouse gases, a time when the mean state is bound to be quite different. Nevertheless, the Holocene provides an important baseline for understanding the natural variability of ENSO. The underlying mechanism, the Bjerknes feedback is likely to be essential in the response of ENSO to many types of forcing. Further studies with a range of models and efforts to collect data from times in the past when the climate was colder will no doubt lead to additional understanding of ENSO and its sensitivity to forcing and to changes in the mean climate state.

\section{The last millennium}

\section{a. Overview}

Anthropogenic climate change is thought to develop on multidecadal to centennial time scales. The comparison of climate simulations of the last millennium and climate reconstructions based on proxy data offers the unique possibility of validating models' ability to simulate climate variations at those time scales. In addition, there is longstanding interest, from historians among others, in climate changes in the last centuries, in particular the Late Maunder Minimum (LMM; around A.D. 1700), which is thought to have been the coldest period in the last millennium (see Jones and Mann 2004, for a recent review).

A number of different forcings may have had an appreciable influence on climate in the last millennium: changes in well-mixed greenhouse gases $\left(\mathrm{CO}_{2}, \mathrm{NO}\right.$, $\mathrm{CH}_{4}$, and various CFCs), changes in land surface characteristics, increases in aerosol loading (both direct effects on albedo and indirect effects through changes in cloud properties), changes in tropospheric and stratospheric ozone, injections of aerosol into the stratosphere following volcanic eruptions, changes in solar irradiance, and changes in the earth's orbital parameters. Among these forcings, the variations in wellmixed greenhouse gases, volcanic activity, solar irradiance, and land use are probably the most important. Unfortunately, apart from the concentrations of greenhouse trace gases, the uncertainty in the magnitude of the changes in these forcings is substantial (Houghton et al. 2001); estimates of variations in past solar irradiance, for example, can diverge by a factor of 5 (Lean et al. 2002).

The bulk of the modeling efforts to date have used EBMs and EMICs-see Jones and Mann (2004) for details. Efforts to simulate the last millennium with state-of-the-art AOGCMs have been limited by the extensive computing required. Since these models are the ones used for climate change prediction, the assessment of their skill to simulate climates other than the present is of paramount importance. Also, the validation of simulations of multidecadal and longer climate variations is critical in detection and attribution studies of anthropogenic climate change.

There have been very few transient simulations of sizable time spans in the last millennium made with coupled ocean-atmosphere GCMs. [Jones and Mann (2004) review some preliminary results.] In general, the simulated variability at centennial time scales tends to be larger than that derived from empirical reconstructions (Jones and Mann 2004). This discrepancy may be due to uncertainties in the external forcing or to uncertainties in the empirical reconstructions. Using "pseudo-proxies" from simulations with coupled models, von Storch et al. (2004) tested the Mann et al. (1998) methodology and found that nonclimatic proxy variability can induce an underestimation of lowfrequency variance. This caveat probably burdens a whole class of empirical reconstruction methods based on ordinary least squares calibration of proxy indicators 
(see also Esper et al. 2005). A critical reassessment of reconstruction methods seems advisable.

Here we present some very recent results of transient simulations of the last centuries obtained with two AOGCMs. More results can be found in Tett et al. (2006), Zorita et al. (2004), von Storch et al. (2004), Two simulations have been carried out with HadCM3 (Pope et al. 2000; Gordon et al. 2000), which has a climate sensitivity of $0.9 \mathrm{~K}\left(\mathrm{~W} \mathrm{~m}^{-2}\right)^{-1}$ (Williams et al. 2001). One simulation initialized from a control simulation (late-nineteenth-century conditions; no changes in natural forcing; Collins et al. 2001) was forced with natural forcings from 1492 to 2000. The second simulation, driven with both natural and anthropogenic forcings, was started in 1750 from the first simulation and integrated through to 2000 (Tett et al. 2006).

A simulation of the period 1000 to 1990 has been done using the ECHAM Hamburg Ocean Primitive Equation (HOPE) model (ECHO-G) driven by natural and anthropogenic forcings (see supplementary information to von Storch et al. 2004 for details). A second ECHO-G simulation forced only by natural forcings and started from this simulation in 1755 was integrated to 1990. The estimated climate sensitivity for ECHO-G,

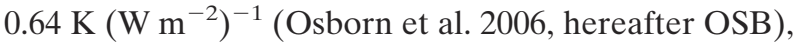
is only $70 \%$ of that of HadCM3.

We focus on the period 1550-2000 in order to reduce the impact of the small initial drift in the HadCM3 simulation (Tett et al. 2006) and the larger drift in the ECHO-G simulation (OSB). The forcings used in the ECHO-G and HadCM3 simulations differ, principally in that the HadCM3 simulations include the warming influence of the hydro- (fluoro-) carbons controlled by the Montreal Protocol and the cooling influences of land surface and sulfate aerosols. Natural forcings also differ from the ECHO-G simulations using a slightly more variable solar forcing than the HadCM3 simulations. The net forcing reduction (including planetary albedo) in the Late Maunder Minimum (1680-1710) relative to present (1960-90) is $0.7(0.6) \mathrm{W} \mathrm{m}^{-2}$ for the forced ECHO-G (HadCM3) simulations. The volcanic forcings differ slightly and are implemented differently. In ECHO-G they modify the solar constant while in HadCM3 volcanic aerosol is directly modeled.

\section{b. Simulated global-mean forcing and Northern Hemisphere surface air temperature}

Figure 11a shows the forcing history for the four simulations relative to the $1700-50$ mean. The natural forcing used in both models is very similar, with the largest differences occurring in the late twentieth century due to the greater increase in solar forcing in the a)

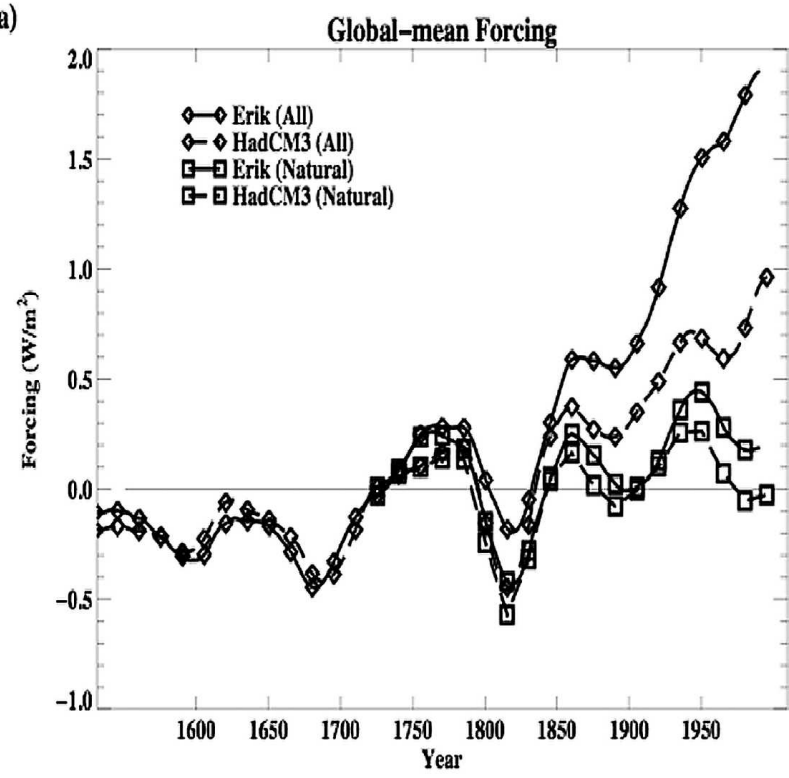

b)

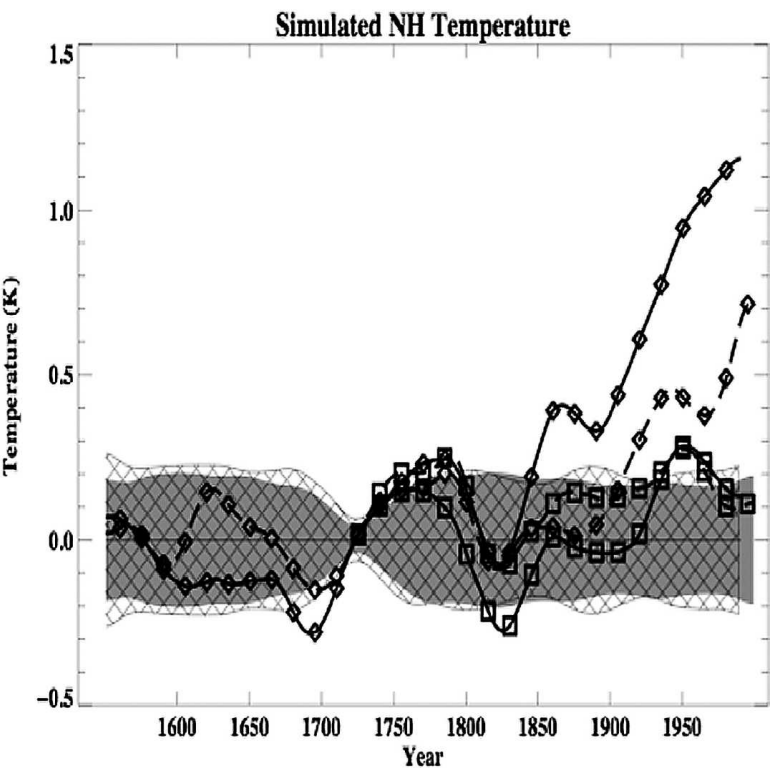

FIG. 11. (a) Global-mean radiative forcings relative to the 1700 49 mean for four simulations (see figure key). Data have been filtered using a 51-yr Gaussian filter that removes periods below 25 yr. (b) Same as in (a), but for NH annual surface air temperature Also shown is $2 \%$ to $98 \%$ range from HadCM3 control (gray) and ECHO-G (cross hatching). Ranges were computed from extrema of the 50-sample bootstrap from 1000- (ECHO-G) and 2400-yr-long (HadCM3) control simulations. Each sample is of length $450 \mathrm{yr}$, treated as started in 1550 and processed as the forced simulations.

ECHO-G simulations. The large negative forcing in the early nineteenth century associated with the eruption of Tambora, the unknown eruption of 1809 , and the Dalton minimum is more negative in the HadCM3 simulations than in the ECHO-G natural simulation. 
Total forcing in the two "ALL" simulations is very different with ECHO-G reaching $2 \mathrm{~W} \mathrm{~m}^{-2}$ by the late twentieth century compared to $1.5 \mathrm{~W} \mathrm{~m}^{-2}$ in the HadCM3 simulation. This difference is largely due to the impact of aerosols and land surface forcing, included in the HadCM3 but not the ECHO-G simulation. Both are concentrated in the Northern Hemisphere. Clearly apparent by the mid-nineteenth century is the clear separation of forcings in the "ALL" simulations from those in the natural simulations. Thus anthropogenic forcings could be having a significant impact by the mid-nineteenth century.

Figure $11 \mathrm{~b}$ shows the evolution of the mean $\mathrm{NH}$ temperature in all four simulations expressed. Both models have similar control variability with ECHO-G having slightly more variability on 50 -yr time scales than does HadCM3. The temperature minima around A.D. 1700 (LMM) and in the early nineteenth century (Dalton Minimum) are clearly simulated, followed by a rapid temperature increase in the twentieth century. Although the forced simulations are quite similar, there are some interesting discrepancies. The natural ECHO-G simulation cools more than the HadCM3 simulation during the early nineteenth century despite having similar global-mean forcing to the HadCM3 simulations (Fig. 11a) and smaller climate sensitivity. This defies expectations based on a simplistic use of climate sensitivity and thus the likely explanation, for this behavior, is that the transient climate sensitivity of ECHO-G is larger than that of HadCM3.

$\mathrm{NH}$ temperatures in the ECHO-G all simulation separate from its "natural" counterpart by the midnineteenth century (Fig. 11b), suggesting a significant anthropogenic influence on climate by the midnineteenth century. The HadCM3 simulations do not apparently separate until the mid-twentieth century, indicating that the aerosols in this model offset some of the greenhouse gas warming. Finally, it is notable that the simulated temperature changes are markedly larger than those inferred from empirical reconstructions.

\section{c. Forced versus unforced variability}

Almost all "detection and attribution" studies (Mitchell et al. 2001) use simulated variability to assess whether the differences between two fields are unlikely to be due to "natural variability" alone. Examples include model-data consistency (Stott et al. 2000), uncertainty ranges in the contribution to twentieth-century climate change from various forcings (Tett et al. 2002), and uncertainties in future climate change (Stott and Kettleborough 2002). The instrumental era is "contaminated" with anthropogenic forcings, making it difficult to test if model variability is truly comparable to nature (but see Allen and Tett 1999). Furthermore, many forcings are acting during the twentieth century. Collins et al. (2002) found that the variability from the HadCM3 control is significantly smaller than that reconstructed from a network of tree ring density proxies. They suggested that the exclusion of external forcings from the simulation is one reason for this discrepancy.

By attempting to simulate the climate variability of the past century using state-of-the-art GCMs, we aim to test the adequacy of the simulated climate variability and to test if the simulated response to external forcings is consistent with that of the natural system. We also aim to see to what extent climate variability is externally forced. One measure is the ratios of forced and unforced ("Control") standard deviations (Fig. 12). We expect the forced simulation variance (and standard deviation) to be larger since forcing adds a response on top of "internal" climate variations. For HadCM3 and ECHO-G the largest enhancement is in the tropical Indian Ocean and West Pacific, regions where ocean dynamics have almost no influence on surface temperature. Note that these are areas that show significant temperature trends over the past few decades (e.g., Hoerling et al. 2001). ECHO-G shows significant enhancement of decadal temperature variability in the extratropics suggesting that natural forcing could significantly enhance variability over the United States and Europe. However, this result is not robust to model formulation as HadCM3 does not show significant enhancement in $\mathrm{NH}$ extratropical variability.

\section{d. Spatial temperature patterns in the LMM}

Figure 13 allows a comparison of simulated and reconstructed (Luterbacher et al. 2004) winter temperature patterns during the LMM, when cooling was widespread in Europe (this shorter ECHO-G simulation begins in 1500; it uses the same external forcings; Zorita el al. 2004). There are departures from the 1550-1880 mean of more than $1.2^{\circ} \mathrm{C}$ in eastern Europe and western Russia, with changes diminishing toward the North Atlantic. The reconstruction compares well with the modeling result. According to a local $t$ test, the cooling is systematic, and not due to random variations, almost everywhere in Europe, Iceland, and southern Greenland, with the exception of northwestern Norway. Both ECHO simulations show a similar cooling pattern. By contrast, HadCM3 (not shown) shows little cooling over Europe despite showing hemispheric cooling during the LMM. The disagreement is probably due to differences in the models or their forcings. However, the HadCM3 result indicates that the sign of regional 
a)

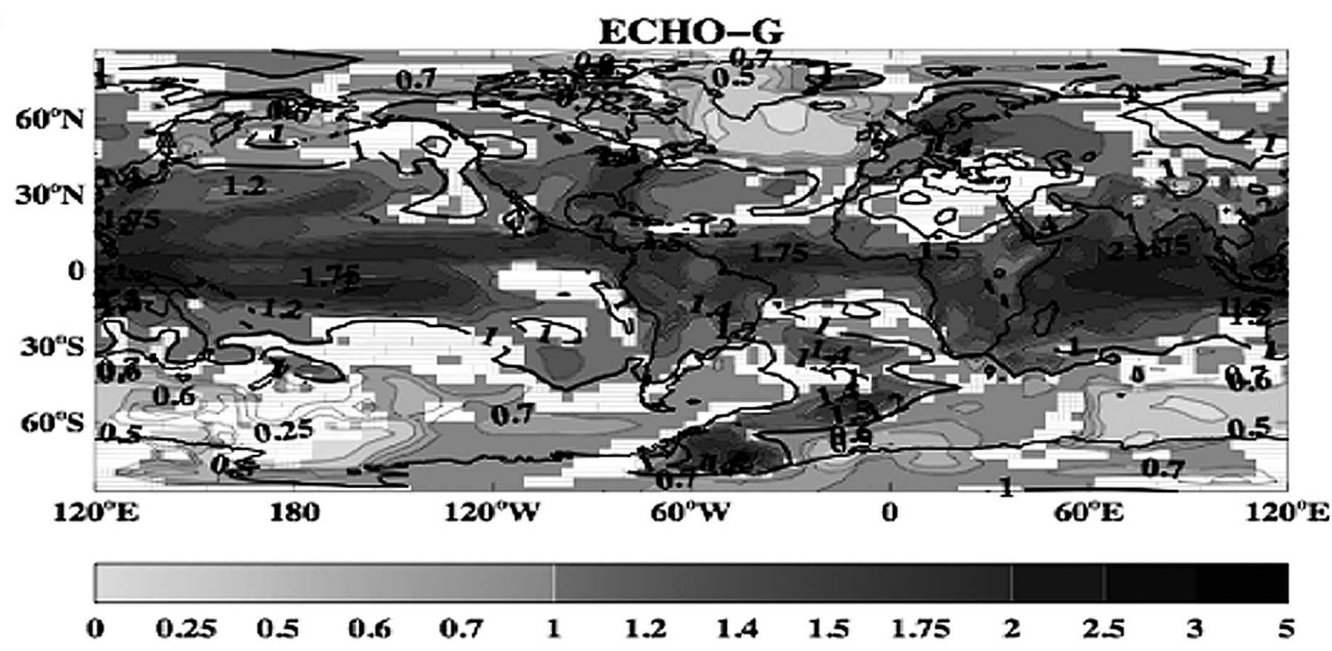

b)

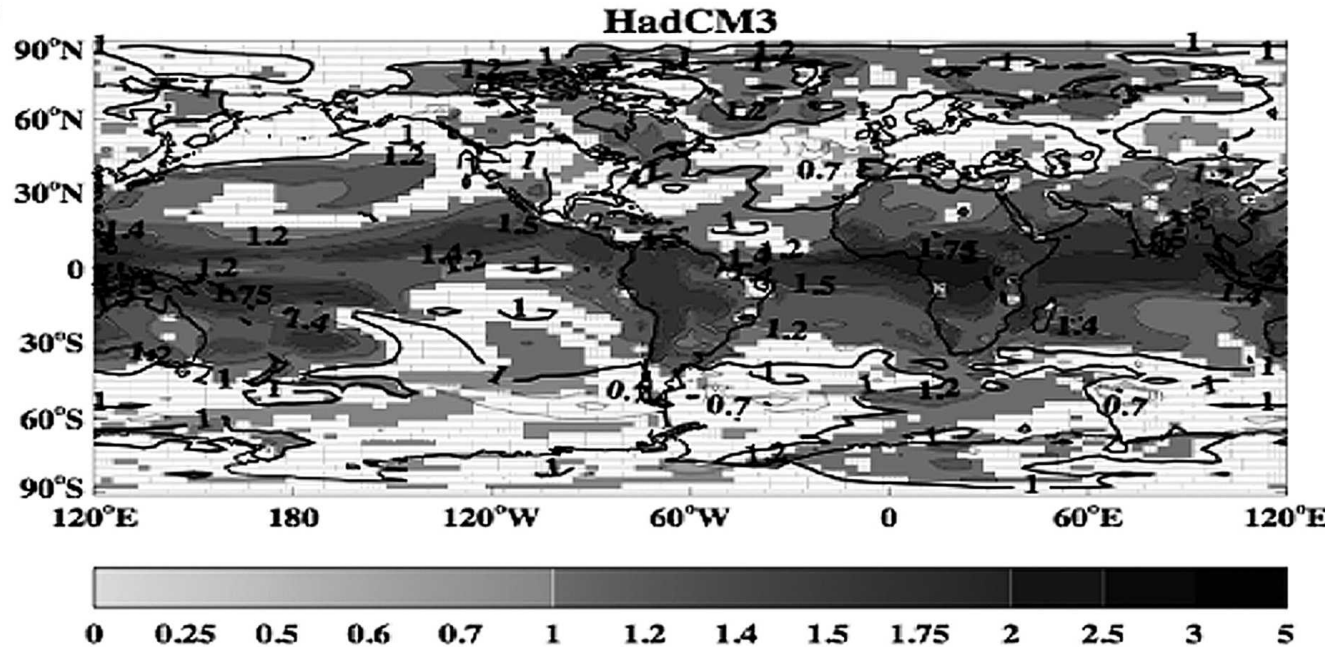

FIG. 12. (a) Ratio of decadal-mean near-surface temperature standard deviation from ECHO-G natural simulation forced with natural forcings to control simulation. Shaded regions show significant (at the $2 \%$ and $98 \%$ level) changes in std dev. (b) Same as in top, but for HadCM3.

climate changes need not follow the global pattern, even in periods like the LMM when global radiative forcing is strong. This could be due to internal, chaotic climate variability; an ensemble of simulations is needed to settle this issue.

\section{e. Outlook}

To compare model simulations with reconstructions a number of uncertainties need to be taken into account.

1) Calibration uncertainty: proxy reconstructions are calibrated against a brief (150 yr) record of instrumental data. Different groups making different assumptions have come to quite different conclusions about the magnitude of climate variability in the preinstrumental record (Esper et al. 2002; Briffa and Osborn 2002; Mann et al. 1998). Quantifying this uncertainty is challenging but critical for comparing simulated and reconstructed forced response. Also, differences between proxy-based and more physically based (e.g., boreholes) reconstructions have to be clarified.

2) Forcing uncertainty: the forcings used to drive models are uncertain and the uncertainties are difficult to quantify. The greatest uncertainty lies in reconstructions of solar irradiance.

3) Chaotic variability: the large chaotic and unpredictable component of variability exhibited in GCMs (and presumably the real climate system) imposes a 


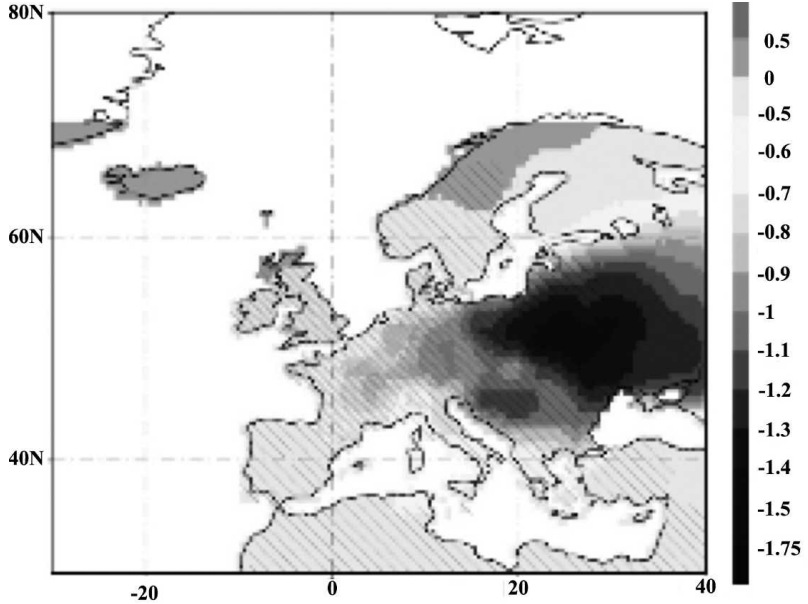

Reconstructed

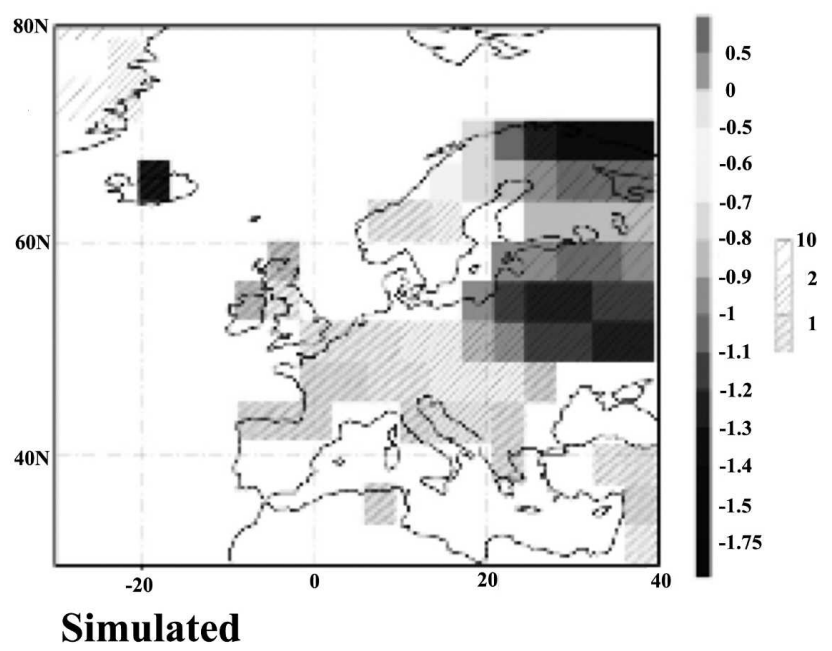

FIG. 13. Winter (DJF) mean temperature departures in the LMM, 1675-1710, from the 1550-1800 mean over Europe. (left) Reconstructed from early instrumental and documentary evidence (derived from Luterbacher et al. 2004); (right) from the ECHO-G simulation. (left) Values over Greenland, Iceland, Scotland, and Scandinavia are positive; reduction of error (RE) statistics, a measure of the skill of the reconstruction, is given by hatching (dense $>0.9$, medium $>0.7$, and light $>0.4$ ). (right) The statistical significance of the model changes, obtained by testing the local null hypothesis of equal means, is indicated by hatching: dense $<1 \%$, medium $<$ $5 \%$, and light $<10 \%$.

need for ensembles of simulations for comparing simulation and reconstructions, greatly increasing computer requirements.

\section{Conclusions}

The greatest concern in climate science is the future, not the past. We are dependent on comprehensive models to forecast what is to come in a climate system we are changing beyond what has been measured in the $\sim 150 \mathrm{yr}$ of the instrumental record. Reliance on our models will sit more comfortably once they have been shown able to simulate the great changes in past climate observed in the paleoproxy record.

Three advances have spurred enormous progress in paleoclimate modeling over the past few decades: the orders of magnitude increase in computing power, the vast increase in the quantity and precision of paleoclimate data, and the improvement in climate models. (This ordering reflects their relative importance, especially since model improvements were facilitated by greater computing power.) The improvements are most heralded in GCMs, but they are equally impressive in intermediate models such as CLIMBER, which make it possible to perform numerous long-term numerical experiments with models that in many respects simulate a credible version of reality.

The history of attempts to simulate glacial inception illustrates how model improvement has enabled scientific progress. Early GCMs and AGCMs all failed to create a permanent snow cover. A breakthrough came when an AGCM was coupled to a mixed layer ocean, but while the beginnings of a glacier were created, other features of the simulation disagreed with data. (Without the paleoproxy data added in recent decades no such model test would have been possible.) Finally, a fully coupled AOGCM gave acceptable agreement with data. The simulation elucidated the physics of glacial inception; $115 \mathrm{kyr}$ B.P. turns out to be the perfect time to grow a glacier, a time when the orbital configuration warms the tropical moisture source while cooling the high northern latitudes in summer.

PMIP has shown that coupling ocean and atmosphere GCMs together has generally improved simulations of the mid-Holocene and Last Glacial Maximum compared with those from AGCMs. The addition of vegetation models has further improved the simulations, especially those of the mid-Holocene increase of the African monsoon. These results have clarified how the interactions of changes in the ocean circulation, and land surface feedbacks, shape the response of the climate system to external forcings. Simulations of the LGM show that there are remaining challenges for climate models; in particular, they still have difficulty with the tropical cooling and the thermohaline circulation changes.

As computer resources increase, it has recently been possible to simulate the last 500 to $1000 \mathrm{yr}$ using stateof-the-art GCMs. We have reported on results using two different models driven by similar forcings. Though 
they show some similarity on long time scales and large space scales they differ in changes on the regional scale. For example, during the Late Maunder Minimum ECHO-G shows cooling over Europe while HadCM3 does not. Ensembles of runs are needed to evaluate how much of this difference may be due to internal variability.

New proxy data have made it worthwhile to simulate ENSO through the Holocene by providing a clear target: in the early and middle Holocene ENSO variability was sharply reduced and, in some accounts, stopped altogether. Model experiments have shown how the influence of orbital forcing in this period was amplified by the Bjerknes feedback to weaken ENSO. Simulations of the LGM, a time with a very different mean state, are more problematic; different models disagree and there is not yet enough data to resolve the issue.

Despite the great leap in computing power it is still out of reach to run a GCM through the long cycles of transitions between glacial and interglacial conditions. It is barely feasible to simulate the $\sim 1500$-yr Dansgaard-Oeschger cycles. The modeling lessons here come from low-order models, which reduce complex physics to schema, and intermediate models, which drastically simplify complex physical processes. They teach us that the cryosphere is an essential element in climate change, and possibly the essential element in abrupt climate change. Any model we trust to foretell the future of the planet must include responsive land and sea ice. The simpler models also teach that the climate system has thresholds where a small change in some external or internal parameter can trigger a large and abrupt change in the climate response. We do not know with certainty what ingredients make the climate system limber enough to flip by $10^{\circ} \mathrm{C}$ or so in no more than a few decades. Could anything like this happen in our greenhouse future? Do our models have the "right stuff" to simulate it?

Acknowledgments. MC is supported by (CICAR) Award NA03OAR4320179 from NOAA. AC was supported by the NSF Paleoclimate program. HG is supported by the Clore Foundation. We thank Bette OttoBliesner, Chris Hewitt, Paul Valdes, and Irina Fast for providing their model results; Jürg Luterbacher for providing the LMM reconstructions; and Pedro de Vries for his first draft of Table 1. The Paleoclimate Modeling Intercomparison Project is endorsed by WCRP/ CLIVAR and IGBP/PAGES. SFBT was funded by the U.K. Government Meteorological Research Contract and, as EZ, by SO\&P (EVK2-CT-2002-00160). We thank Virginia DiBlasi-Morris for editing and Jeewan Naik for his help.

\section{REFERENCES}

AchutaRao, K., and K. R. Sperber, 2002: Simulation of the El Niño Southern Oscillation: Results from the Coupled Model Intercomparison Project. Climate Dyn., 19, 191-209.

Allen, M. R., and S. F. B. Tett, 1999: Checking for model consistency in optimal finger printing. Climate Dyn., 15, 419-434.

Alley, R. B., 2003: Comment on "When Earth's freezer door is left ajar." Eos, Trans. Amer. Geophys. Union, 85, 315.

- E. J. Brook, and S. Anandakrishnan, 2002: A northern lead in the orbital band north-south phasing of ice-age events. Quat. Sci. Rev., 21, 431-441.

Ashkenazy, Y., D. R. Baker, H. Gildor, and S. Havlin, 2003: Nonlinearity and multifractality of climate change in the past 420, 000 years. Geophys. Res. Lett., 30, 2146, doi:10.1029/ 2003GL018099.

,-- , and — 2005: Simple stochastic models for glacial dynamics. J. Geophys. Res., 110, C02005, doi:10.1029/ 2004JC002548.

Barber, D. C., and Coauthors, 1999: Forcing of the cold event 8200 years ago by outburst drainage of Laurentide lakes. Nature, 400, 344-348.

Bassinot, F. C., L. D. Labeyrie, E. Vincent, X. Quidelleur, N. J. Shackleton, and Y. Lancelot, 1994: The astronomical theory of climate and the age of the Brunhes-Matuyama magnetic reversal. Earth Planet. Sci. Lett., 126, 91-108.

Benzi, R., G. Parisi, A. Sutera, and A. Vulpiani, 1982: Stochastic resonance in climatic change. Tellus, 34, 10-16.

Bjerknes, J., 1966: A possible response of the atmospheric Hadley circulation to equatorial anomalies of ocean temperature. Tellus, 18, 820-829.

_ 1969: Atmospheric teleconnections from the equatorial $\mathrm{Pa}-$ cific. Mon. Wea. Rev., 97, 163-172.

Bond, G., W. Broecker, S. Johnsen, J. McManus, L. Labeyrie, J. Jouzel, and G. Bonani, 1993: Correlations between climate records from North Atlantic sediments and Greenland ice. Nature, 365, 143-147.

_ , and Coauthors, 2001: Persistent solar influence on North Atlantic climate during the holocene. Science, 294, 21302136.

Braconnot, P., and O. Marti, 2003: Impact of precession on monsoon characteristics from coupled ocean atmosphere experiments: Changes in Indian monsoon and Indian ocean climatology. Mar. Geol., 201, 23-34.

_, S. Joussaume, O. Marti, and N. de Noblet, 1999: Synergistic feedbacks from ocean and vegetation on the African monsoon response to mid-Holocene insolation. Geophys. Res. Lett., 26, 2481-2484.

—- and Coauthors, 2004: Evaluation of coupled oceanatmosphere simulations of the mid-Holocene. Past Climate Variability through Europe and Africa, R. W. Battarbee et al., Eds., Kluwer Academic, 515-523.

Briffa, K. R., and T. J. Osborn, 2002: Blowing hot and cold. Science, 295, 2227-2228.

Broecker, W. S., and G. H. Denton, 1990: The role of the oceanatmosphere reorganizations in glacial cycles. Quat. Sci. Rev., 9, 305-341.

Calov, R., A. Ganopolski, V. Petoukhov, M. Claussen, and R. Greve, 2002: Large-scale instabilities of the Laurentide ice sheet simulated in a fully coupled climate-system model. Geophys. Res. Lett., 29, 2216, doi:10.1029/2002GL016078.

Cane, M. A., 1998: A role for the Tropical Pacific. Science, 282, $59-61$. 
Chapman, M. R., and N. J. Shackleton, 1999: Global ice-volume fluctuations, North Atlantic ice-rafting events, and deepocean circulation changes between 130 and 70 ka. Geology, 27, 795-798.

Clark, P. U., S. J. Marshall, G. K. C. Clarke, S. W. Hostetler, J. M. Licciardi, and J. T. Teller, 2001: Freshwater forcing of abrupt climate change during the last glaciation. Science, 293, 283287.

Clement, A. C., R. Seager, and M. A. Cane, 2000: Suppression of El Niño during the mid-Holocene by changes in the earth's orbit. Paleoceanography, 15, 731-737.

CLIMAP, 1981: Seasonal Reconstructions of the Earth's Surface at the Last Glacial Maximum. Map Chart Series, MC-36, Geological Society of America, $18 \mathrm{pp}$.

Collins, M., S. F. B. Tett, and C. Cooper, 2001: The internal climate variability of HadCM3, a version of the Hadley Centre coupled model without flux adjustments. Climate Dyn., 17, 61-81.

— T. J. Osborn, S. F. B. Tett, K. R. Brifa, and F. H. Schweingruber, 2002: A comparison of the variability of a climate model with a network of tree-ring densities. J. Climate, 15, 1497-1515.

Cortijo, E., and Coauthors, 1997: Changes in sea surface hydrology associated with Heinrich event 4 in the North Atlantic Ocean between $40^{\circ} \mathrm{N}$ and $60^{\circ} \mathrm{N}$. Earth Planet. Sci. Lett., 146, 29-45.

— - S. Lehman, L. Keigwin, M. Chapman, D. Paillard, and L. Labeyrie, 1999: Changes in meridional temperature and salinity gradients in the North Atlantic Ocean $\left(30^{\circ}-72^{\circ} \mathrm{N}\right)$ during the last interglacial period. Paleoceanography, 14, 23-33.

Crowley, T. J., 2000: Causes of climate change over the past 1000 years. Science, 289, 270-277.

Crucifix, M., and M. F. Loutre, 2002: Transient simulations over the last interglacial period (126-115 kyr BP): Feedback and forcing analysis. Climate Dyn., 19, 417-433.

Dansgaard, W., J. W. C. White, and S. J. Johnsen, 1989: The abrupt termination of the Younger Dryas climate event. $\mathrm{Na}$ ture, 339, 532-534.

DeNoblet, N., I. C. Prentice, S. Joussaume, D. Texier, A. Botta, and A. Haxeltine, 1996: Possible role of atmospherebiosphere interactions in triggering the last glaciation. Geophys. Res. Lett., 23, 3191-3194.

Dong, B., and P. J. Valdes, 1995: Sensitivity studies of Northern Hemisphere glaciation using an atmospheric general circulation model. J. Climate, 8, 2471-2495.

Elkibbi, M., and J. A. Rial, 2001: As outsider's review of the astronomical theory of climate: Is the eccentricity-driven insolation the main driver of the ice ages? Earth Sci. Rev., 56, 161-177.

Esper, J., E. R. Cook, and F. H. Schweingruber, 2002: Lowfrequency signals in long tree-ring chronologies for reconstructing past temperature variability. Science, 295, 22502253.

—, D. Frank, R. S. Wilson, and K. R. Briffa, 2005: Effect of scaling and regression on reconstructed temperature amplitude for the past millennium. Geophys. Res. Lett., 32, L07711, doi:10.1029/2004GL021236.

Fine, R. A., W. H. Peterson, and H. G. Ostlund, 1987: The penetration of tritium into the tropical Pacific. J. Phys. Oceanogr., 17, 553-564.

Gagan, M. K., L. D. Ayliffe, D. Hopley, J. A. Cale, G. E. Mortimer, J. Chappell, M. T. McCulloch, and M. J. Head, 1998:
Temperature and surface-ocean water balance of the MidHolocene tropical western Pacific. Science, 279, 1014-1018.

Gallimore, R. G., and J. E. Kutzbach, 1996: Role of orbitally induced changes in tundra area in the onset of glaciation. $\mathrm{Na}$ ture, 381, 503-505.

Ganopolski, A., and S. Rahmstorf, 2001: Rapid changes of glacial climate simulated in a coupled climate model. Nature, $\mathbf{4 0 9}$, 153-158.

- , and - 2002: Abrupt glacial climate changes due to stochastic resonance. Phys. Rev. Lett., 88, 038 501, doi:10.1103/ PhysRevLett.88.038501.

,,-- V. Petoukhov, and M. Claussen, 1998: Simulation of modern and glacial climates with a coupled global model of intermediate complexity. Nature, 391, 351-356.

Ghil, M., A. Mullhaupt, and P. Pestiaux, 1987: Deep water formation and Quaternary glaciations. Climate Dyn., 2, 1-10.

Gildor, H., 2003a: When Earth's freezer door is left ajar. Eos, Trans. Amer. Geophys. Union, 84, 215-216.

— 2003b: Reply to comment on "When Earth's freezer door is left ajar" by Richard B. Alley. Eos, Trans. Amer. Geophys. Union, 84, 315.

— , and E. Tziperman, 2000: Sea ice as the glacial cycles' climate switch: Role of seasonal and orbital forcing. Paleoceanography, 156, 605-615.

— cal glacial-interglacial $\mathrm{CO}_{2}$ variations. Geophys. Res. Lett., 28, 2421-2424.

— and _ 2001b: A sea-ice climate-switch mechanism for the 100 kyr glacial cycles. J. Geophys. Res., 106, 9117-9133.

— , and M. Ghil, 2002: Phase relations between climate proxy records Potential effect of seasonal precipitation changes. Geophys. Res. Lett., 29, 1024, doi:10.1029/2001GL013781.

_ E. Tziperman, and R. J. Toggweiler, 2002: Sea ice switch mechanism and glacial-interglacial $\mathrm{CO}_{2}$ variations. Global Biogeochem. Cycles, 16, 1032, doi:10.1029/2001GB001446.

Gordon, C., C. Cooper, C. A. Senior, H. Banks, J. M. Gregory, T. C. Johns, J. F. B. Mitchell, and R. A. Wood, 2000: The simulation of SST, sea ice extent and ocean heat transport in a version of the Hadley Centre coupled model without flux adjustments. Climate Dyn., 16, 147-168.

Gu, D. F., and S. G. H. Philander, 1997: Interdecadal climate fluctuations that depend on exchanges between the tropics and extratropics. Science, 275, 805-807.

Harrison, S., 2000: Paleoenvironmental data set and model evaluation in PMIP. Proc. Third PMIP Workshop, Vol. WCRP111, WMO/TD-No. 1007, La Huardière, QC, Canada, 25-42.

- and C. Prentice, 2003: Climate and $\mathrm{CO}_{2}$ controls on global vegetation distribution at the last glacial maximum: Analysis based on paleovegetation data, biome modelling and paleoclimate simulations. Global Change Biol., 9, 983-1004.

, and Coauthors, 1998: Intercomparison of simulated global vegetation distributions in response to $6 \mathrm{kyr} \mathrm{BP}$ orbital forcing. J. Climate, 11, 2721-2742.

Haug, G. H., K. A. Hughen, D. M. Sigman, L. C. Peterson, and U. Rohl, 2001: Southward migration of the intertropical convergence zone through the Holocene. Science, 293, 1304-1308.

Hewitt, C. D., A. J. Broccoli, J. F. B. Mitchell, and R. J. Stouffer, 2001: A coupled model study of the last glacial maximum: Was part of the North Atlantic relatively warm? Geophys. Res. Lett., 28, 1571-1574.

Hoerling, P. M., J. W. Hurell, and T. Xu, 2001: Tropical origins for recent North Atlantic climate change. Science, 292, 90-92.

Houghton, J. T., Y. Ding, D. J. Griggs, M. Noguer, P. J. van der 
Linden, X. Dai, K. Maskell, and C. A. Johnson, Eds., 2001: Climate Change 2001: The Scientific Basis. Cambridge University Press, $881 \mathrm{pp}$.

Imbrie, J., and J. Z. Imbrie, 1980: Modeling the climatic response to orbital variations. Science, 207, 943-953.

— mate: Support from a revised chronology of the marine ${ }^{18} \mathrm{O}$ record. Milankovitch and Climate, Part 1, A. Berger et al., Eds., Riedel, 269-305.

— - and Coauthors, 1993: On the structure and origin of major glaciation cycles 2. The 100,000-year cycle. Paleoceanography, 8, 699-735.

Jones, P. D., and M. E. Mann, 2004: Climate over past millennia. Rev. Geophys., 42, RG2002, doi:10.1029/2003RG000143.

Jost, A., D. Lunt, M. Kageyama, A. Abe-Ouchi, O. Peyron, P. J. Valdes, and G. Ramstein, 2005: High-resolution simulations of the last glacial maximum climate over Europe: A solution to discrepancies with continental palaeoclimatic reconstructions? Climate Dyn., 24, 577-590.

Joussaume, S., and Coauthors, 1999: Monsoon changes for 6000 years ago: Results of 18 simulations from the Paleoclimate Modeling Intercomparison Project (PMIP). Geophys. Res. Lett., 26, 859-862.

Kageyama, M., and D. Paillard, 2005: Dansgaard-Oeschger events: An oscillation of the climate-ice-sheet system? C. R. Geosci., 337, 993-1000.

— , P. J. Valdes, G. Ramstein, C. Hewitt, and U. Wyputta, 1999: Northern Hemisphere storm tracks in present day and last glacial maximum climate simulations: A comparison of the European PMIP models. J. Climate, 12, 742-760.

—_, and Coauthors, 2006: Last Glacial Maximum temperatures over the North Atlantic, Europe and western Siberia: A comparison between PMIP models, MARGO sea-surface temperatures and pollen-based reconstructions. Quat. Sci. Rev., in press.

Källén, K., C. Crafoord, and M. Ghil, 1979: Free oscillations in a climate model with ice-sheet dynamics. J. Atmos. Sci., 36, 2292-2303.

Karner, D. B., and R. A. Muller, 2000: Paleoclimate-A causality problem for Milankovitch. Science, 288, 2143-2144.

Keeling, R. F., and B. B. Stephens, 2001: Antarctic sea ice and the control of Pleistocene climate instability. Paleoceanography, 16, 112-131.

Kennett, J. P., K. G. Cannariato, I. L. Hendy, and R. J. Behl, 2000: Carbon isotopic evidence for methane hydrate instability during quaternary interstadials. Science, 288, 128-133.

Khodri, M., Y. Leclainche, G. Ramstein, P. Braconnot, O. Marti, and E. Cortijo, 2001: Simulating the amplification of orbital forcing by ocean feedbacks in the last glaciation. Nature, 410, 570-574.

— , G. Ramstein, D. Paillard, J. C. Duplessy, M. Kageyama, and A. Ganopolski, 2003: Modelling the climate evolution from the last interglacial to the start of the last glaciation: The role of Arctic Ocean freshwater budget. Geophys. Res. Lett., 30, 1606, doi:10.1029/2003GL017108.

Kim, S. J., G. M. Flato, and G. J. Boer, 2003: A coupled climate model simulation of the last glacial maximum, Part 2: Approach to equilibrium. Climate Dyn., 20, 635-661.

Kitoh, A., and S. Murakami, 2002: Tropical Pacific climate at the mid-Holocene and the Last Glacial Maximum simulated by a coupled ocean-atmosphere general circulation model. Paleoceanography, 17, 1047, doi:10.1029/2001PA000724.

_ - S. Murakami, and H. Koide, 2001: A simulation of the Last
Glacial Maximum with a coupled atmosphere-ocean GCM. Geophys. Res. Lett., 28, 2221-2224.

Kohfeld, K. E., and S. P. Harrison, 2001: DIRTMAP: The geological record of dust. Earth Sci. Rev., 54, 81-114.

Lambeck, K., and J. Chappell, 2001: Sea level change through the last glacial cycle. Science, 292, 686-697.

Latif, M., and ENSIP Group, 2001: The El Niño simulation intercomparison project. Climate Dyn., 18, 255-276.

Lean, J. L., Y.-M. Wang, and N. R. Sheely Jr., 2002: The effect of increasing solar activity on the Sun's total and open magnetic flux during multiple cycles: Implications for solar forcing of climate. Geophys. Res. Lett., 29, 2224, doi:10.1029/ 2002GL015880.

Le-Treut, H., and M. Ghil, 1983: Orbital forcing, climatic interactions, and glaciations cycles. J. Geophys. Res., 88, 51675190.

Levis, S., J. A. Foley, and D. Pollard, 1999: $\mathrm{CO}_{2}$, climate, and vegetation feedbacks at the Last Glacial Maximum. J. Geophys. Res., 104D, 31 191-31 198.

Liu, Z., S. G. H. Philander, and R. C. Pacanowski, 1994: A GCM study of tropical-subtropical upper-ocean water exchange. $J$. Phys. Oceanogr., 24, 2606-2623.

- J. Kutzbach, and L. Wu, 2000: Modeling the climatic shift of El Niño variability in the Holocene. Geophys. Res. Lett., 27, 2265-2268.

, S. Shin, B. L. Otto-Bliesner, J. Kutzbach, E. C. Brady, and D. E. Lee, 2002: Tropical cooling at the last glacial maximum and extratropical ocean ventilation. Geophys. Res. Lett., 29, 1409, doi:10.1029/2001GL013938.

Lu, P., and J. P. McCreary, 1995: Influence of the ITCZ on the flow of thermocline water from the subtropical to the equatorial ocean. J. Phys. Oceanogr., 25, 3076-3088.

Luterbacher, J., D. Dietrich, E. Xoplaki, M. Grosjean, and H. Wanner, 2004: European seasonal and annual temperature variability: Trends and extremes since 1500. Science, 203, 1499-1503.

MacAyeal, D. R., 1993: A low-order model of the Heinrich event cycle. Paleoceanography, 8, 767-773.

Mahowald, N., K. E. Kohfeld, M. Hansson, Y. Balkanski, S. P. Harrison, I. C. Prentice, M. Schulz, and H. Rodhe, 1999: Dust sources and deposition in the Last Glacial Maximum and current climate: A comparison of model results with paleodata from ice cores and marine sediments. J. Geophys. Res., 104D, 15 895-15 916.

Mann, M. E., R. S. Bradley, and M. K. Hughes, 1998: Global-scale temperature patterns and climate forcing of the past six centuries. Science, 392, 779-787.

,-- , and -2004 : Corrigendum: Global-scale temperature patterns and climate forcing over the past six centuries. Nature, 430, 105, doi:10.1038/nature02478.

Maslin, M., D. Seidov, and J. Lowe, 2001: Synthesis of the nature and causes of rapid climate transitions during the Quaternary. The Oceans and Rapid Climate Change: Past, Present, and Future, Geophys. Monogr., M. Maslin, Ed., Vol. 126, Amer. Geophys. Union, 9-52.

McGlone, M. S., A. P. Kershaw, and V. Margraf, 1992: El Niño/ Southern Oscillation climatic variability in Australasian and South American paleoenvironmental records. El Niño: Historical and Paleoclimatic Apsects of the Southern Oscillation, H. F. Diaz and V. Margraf, Eds., Cambridge University Press, 435-462.

McManus, J. F., D. W. Oppo, L. D. Keigwin, J. L. Cullen, and G. C. Bond, 2002: Thermohaline circulation and prolonged 
interglacial warmth in the North Atlantic. Quat. Res., 58, $17-21$.

Milankovitch, M., 1941: Canon of Insolation and the Ice-Age Problem. Royal Serbian Academie Special Publications, Vol. 132, 633 pp.

Mitchell, J. F. B., D. J. Karoly, G. C. Hegerl, F. W. Zwiers, M. R. Allen, and J. Marengo, 2001: Detection of climate change and attribution of causes. Climate Change 2001: The Scientific Basis, J. T. Houghton et al., Eds., Cambridge University Press, 697-738.

Mix, A. C., E. Bard, and R. Schneider, 2001: Environmental processes of the ice age: Land, oceans, glaciers (EPILOG). Quat. Sci. Rev., 20, 627-657.

Moy, C. M., G. O. Seltzer, D. T. Rodbell, and D. M. Anderson, 2002: Variability of El Niño/Southern Oscillation activity at millennial timescales during the Holocene epoch. Nature, 420, 162-165.

Muller, R. A., and G. J. McDonald, 1995: Glacial cycles and orbital inclination. Nature, 377, 107-108.

Oerlemans, J., 1982: Glacial cycles and ice-sheet modeling. Climate Change, 4, 353-374.

Oppo, D. W., L. D. Keigwin, J. F. McManus, and J. L. Cullen, 2001: Persistent suborbital climate variability in marine isotope stage 5 and Termination II. Paleoceanography, 16, 280292.

Osborn, T. J., S. C. B. Raper, and K. R. Briffa, 2006: Simulated climate change during the last 1000 years: Comparing the ECHO-G general circulation model with the MAGICC simple climate model. Climate Dyn., 27, 185-197.

Otto-Bliesner, B. L., 1999: El Niño, La Niña and Sahel precipitation during the middle Holocene. Geophys. Res. Lett., 26, 87-90.

_ E. C. Brady, S.-I. Shin, Z. Liu, and C. Shields, 2003: Modeling El Niño and its tropical teleconnections during the last glacial-interglacial cycle. Geophys. Res. Lett., 30, 2198, doi:10.1029/2003GL018553.

Paillard, D., 1998: The timing of Pleistocene glaciations from a simple multiple-state climate model. Nature, 391, 378-381.

_ - 2001: Glacial cycles toward a new paradigm. Rev. Geophys., 39, 325-346.

—_, 2004: Modéliser les événements rapides au sein du système climatique. C. R. Geosci., 336, 733-740.

— , and L. Labeyrie, 1994: Role of the thermohaline circulation in the abrupt climate warming after Heinrich events. Nature, 372, 162-164.

— onal circulation during Heinrich event 4 using reconstructed sea surface temperatures and salinities. Paleoceanography, 14, 716-724.

Parrenin, F., and D. Paillard, 2003: Amplitude and phase of glacial cycles from a conceptual model. Earth Planet. Sci. Lett., 214, 243-250.

Pelletier, J. D., 2003: Coherence resonance and ice ages. J. Geophys. Res., 108, 4645, doi:10.1029/2002JD003120.

Peterson, L. C., G. H. Haug, K. A. Hughen, and U. Röhl, 2000: Rapid changes in the hydrologic cycle of the tropical Atlantic during the last glacial. Science, 290, 1947-1951.

Petit, J. R., and Coauthors, 1999: Climate and atmospheric history of the past 420, 000 years from the Vostok ice core, Antarctica. Nature, 399, 429-436.

Pinot, S., G. Ramstein, S. P. Harrison, I. C. Prentice, J. Guiot, M. Stute, and S. Joussaume, 1999: Tropical paleoclimates at the Last Glacial Maximum: Comparison of Paleoclimate Model- ing Intercomparison Project (PMIP) simulations and paleodata. Climate Dyn., 15, 857-874.

PMIP, 2000: Paleoclimate Modeling Intercomparison Project (PMIP): Proc. Third PMIP Workshop. WCRP-111, WMO/ TD-1007, La Hudière, QC, Canada, 271 pp.

Pons, A., J. Guiot, J. de Beaulieu, and M. Reille, 1992: Recent contributions to the climatology of the last glacial interglacial Cycle based on French pollen sequences. Quat. Sci. Rev., 11, 439-448.

Pope, V. P., M. L. Gallini, P. R. Rowntree, and R. A. Stratton, 2000: The impact of new physical parameterizations in the Hadley Centre climate model. Climate Dyn., 16, 123-146.

Prange, M., V. Romanova, and G. Lohmann, 2002: The glacial thermohaline circulation: Stable or unstable? Geophys. Res. Lett., 29, 2028, doi:10.1029/2002GL015337.

Rahmstorf, S., 2003: Timing of abrupt climate change: A precise clock. Geophys. Res. Lett., 30, 1510, doi:10.1029/ 2003GL017115.

Rajagopalan, B., U. Lall, and M. A. Cane, 1997: Anomalous ENSO occurrences: An alternate view. J. Climate, 10, 23512357.

Rittenour, T. M., J. Brigham-Grette, and M. E. Mann, 2000: El Niño-like climate teleconnections in New England during the late Pleistocene. Science, 288, 1039-1042.

Rodbell, D., G. Seltzer, D. Anderson, M. Abbott, D. Enfield, and J. Newman, 1999: An 15,000 year record of El Niño-driven alluviation in southwestern Ecuador. Science, 283, 516-520.

Rodgers, K. B., M. A. Cane, N. H. Naik, and D. P. Schrag, 1999: The role of the Indonesian throughflow in equatorial Pacific thermocline ventilation. J. Geophys. Res., 104, 20 551-20 570.

- B. Blanke, G. Madec, O. Aumont, P. Ciais, and J. C. Dutay, 2003: Extratropical sources of equatorial Pacific upwelling in an OGCM. Geophys. Res. Lett., 30, 1084, doi:10.1029/ 2002GL016003.

Roe, G. H., and M. R. Allen, 1999: A comparison of competing explanations for the 100,000-yr ice age cycle. Geophys. Res. Lett., 26, 2259-2262.

Saltzman, B., and R. E. Moritz, 1980: A time dependent climatic feedback system involving sea-ice extent, ocean temperature, and $\mathrm{CO}_{2}$. Tellus, 32, 93-117.

_ , and A. Sutera, 1984: A model of the internal feedback system involved in Late Quaternary climatic variations. J. Atmos. Sci., 41, 736-745.

_ _ and K. A. Maasch, 1988: Carbon cycle instability as a cause of the late pleistocene ice age oscillation: Modeling the asymmetric response. Global Biogeochem. Cycles, 2, 177-185.

_ A. R. Hansen, and K. A. Maasch, 1984: The late Quaternary glaciations as the response of a three-component feedback system to Earth-orbital forcing. J. Atmos. Sci., 41, 3380-3389.

Sànchez-Goñi, M., F. Eynaud, J. Turon, and N. Shackleton, 1999: High resolution palynological record off the Iberian margin: Direct land-sea correlation for the last interglacial complex. Earth Planet. Sci. Lett., 171, 123-137.

Sandweiss, D. H., J. B. Richardson, E. J. Reitz, and H. B. Rollins, 1996: Geoarchaeological evidence from Peru for a 5000 year B.P. onset of El Niño. Science, 273, 1531-1533.

_, K. A. Maasch, R. L. Burger, J. B. Richardson, H. B. Rollins, and A. C. Clement, 2001: Variation in Holocene El Niño frequencies: Climate records and cultural consequences in ancient Peru. Geology, 29, 603-606.

Sayag, R., E. Tziperman, and M. Ghil, 2004: Rapid switch-like sea ice growth and land ice-sea ice hysteresis. Paleoceanography, 19, PA1021, doi:10.1029/2003PA000946. 
Schmittner, A., M. Yoshimori, and A. J. Weaver, 2002: Instability of glacial climate in a model of the ocean-atmospherecryosphere system. Science, 295, 1489-1493.

Schulz, H., U. von Rad, and H. Erlenkeuser, 1998: Correlation between Arabian Sea and Greenland climate oscillations of the past 110, 000 years. Nature, 393, 54-57.

Shackleton, N. J., 1987: Oxygen isotopes, ice volume and sea level. Quat. Sci. Rev., 6, 183-190.

—-, M. Chapman, M. Sànchez-Goñi, D. Pailler, and Y. Lancelot, 2002: The classic marine isotope substage 5e. Quat. Res., 58, $14-16$.

Shin, S. I., Z. Liu, B. Otto-Bliesner, E. C. Brady, J. E. Kutzbach, and S. P. Harrison, 2003a: A simulation of the last glacial maximum climate using the NCAR-CCSM. Climate Dyn., 20, $127-151$.

,,,--- J. E. Kutzbach, and S. J. Vavrus, 2003b: Southern Ocean sea-ice control of the glacial North Atlantic thermohaline circulation. Geophys. Res. Lett., 30, 1096, doi:10.1029/2002GL015513.

Shulmeister, J., and B. G. Lees, 1995: Pollen evidence from tropical Australia for the onset of an ENSO dominated climate at c. 4000 BP. Holocene, 5, 10-18.

Stott, P. A., and J. A. Kettleborough, 2002: Origins and estimates of uncertainty in predictions of twenty-first century temperature rise. Nature, 416, 723-726.

— S. F. B. Tett, G. S. Jones, M. R. Allen, J. F. B. Mitchell, and G. J. Jenkins, 2000: External control of 20th century temperature variations by natural and anthropogenic forcings. Science, 15, 2133-2137.

Tarasov, L., and W. R. Peltier, 1997: Terminating the $100 \mathrm{kyr}$ ice age cycle. J. Geophys. Res., 102, 21 665-21 693.

— , and _ 1999: The impact of thermomechanical ice-sheet coupling on a model of the $100 \mathrm{kyr}$ ice-age cycle. J. Geophys. Res., 104, 9517-9545.

Tett, S. F. B., and Coauthors, 2002: Estimation of natural and anthropogenic contributions to twentieth century temperature change. J. Geophys. Res., 107, 4306, doi:10.1029/ 2000JD000028.

—- and Coauthors, 2006: The impact of natural and anthropogenic forcings on climate and hydrology since 1550. Climate Dyn., in press.

Timmermann, A., H. Gildor, M. Schultz, and E. Tziperman, 2003: Coherent resonant millennial-scale climate oscillations triggered by glacial meltwater pulses. J. Climate, 16, 2569-2585.

Trenberth, K. E., and T. J. Hoar, 1996: The 1990-1995 El NiñoSouthern Oscillation event: Longest on record. Geophys. Res. Lett., 23, 57-60.

Tsimring, L. S., and A. Pikovsky, 2001: Noise-induced dynamics in bistable systems with delay. Phys. Rev. Lett., 87, 250 602, doi:10.1103/PhysRevLett.87.250602.

Tudhope, A. W., and Coauthors, 2001: Variability in the El Niño-
Southern Oscillation through a glacial-interglacial cycle. Science, 291, 1511-1517.

Tzedakis, P. C., M. R. Frogley, and T. H. Heaton, 2002: Duration of the last interglacial conditions in northwestern Greece. Quat. Res., 58, 53-55.

Tziperman, E., 2001: Mechanisms and toy models of the glacial cycles. Conceptual Models of the Climate: GFD Proc. Volume 2001, Woods Hole, MA, Woods Hole Oceanographic Institution. [Available online at http://gfd.whoi.edu/proceedings/ 2001/PDFvol2001.html.]

Vettoretti, G., and W. R. Peltier, 2003: Post-Eemian glacial inception. Part I: The impact of summer seasonal temperature bias. J. Climate, 16, 889-911.

von Storch, H. E. Zorita, J. Jones, Y. Dimitriev, J. F. GonzalezRouco, and S. F. B. Tett, 2004: Reconstructing past climates from noisy data. Science, 306, 679-682.

Wang, Z., and L. A. Mysak, 2002: Simulation of the last glacial inception and rapid ice sheet growth in the McGill Paleoclimate Model. Geophys. Res. Lett., 29, 2102, doi:10.1029/ 2002GL015120.

— - - and J. F. McManus 2002: Response of the thermohaline circulation to cold climates. Paleoceanography, 17, 1006, doi:10.1029/2000PA000587.

Weaver, A. J., M. Eby, A. F. Fanning, and E. C. Wiebe, 1998: Simulated influence of carbon dioxide, orbital forcing and ice sheets on the climate of the Last Glacial Maximum. Nature, 394, 847-853.

—, O. A. Saenko, P. U. Clark, and J. X. Mitrovica, 2003: Meltwater Pulse 1A from Antarctica as a trigger of the BøllingAllerød warm interval. Science, 299, 1709-1713.

Williams, K. D., C. A. Senior, and J. F. B. Mitchell, 2001: Transient climate change in the Hadley Centre models: The role of physical processes. J. Climate, 14, 659-674.

Wohlfahrt, J., S. P. Harrison, and P. Braconnot, 2004: Synergistic feedbacks between ocean and vegetation on mid- and highlatitude climates during the mid-Holocene. Climate Dyn., 22, 223-238.

Wunsch, C., 2003: The spectral description of climate change including the 100 ky energy. Climate Dyn., 20, 353-363.

Zebiak, S. E., and M. A. Cane, 1987: A model El Niño/Southern Oscillation. Mon. Wea. Rev., 115, 2262-2278.

Zhao, Y., and Coauthors, 2005: A multi-model analysis of the role of the ocean on the African and Indian monsoon during the mid-Holocene. Climate Dyn., 25, 777-800.

Zorita, E., H. von Storch, F. Gonzalez-Rouco, U. Cubasch, J. Luterbacher, I. Fischer-Bruns, S. Legutke, and U. Schlese, 2004: Climate evolution in the last five centuries simulated by an atmosphere-ocean model: Global temperatures, the North Atlantic Oscillation and the Late Maunder Minimum. Meteor. Z., 13, 271-289. 
Copyright of Journal of Climate is the property of American Meteorological Society and its content may not be copied or emailed to multiple sites or posted to a listserv without the copyright holder's express written permission. However, users may print, download, or email articles for individual use. 